\title{
A Data Assimilation Case Study Using a Limited-Area Ensemble Kalman Filter
}

\author{
Sébastien Dirren, Ryan D. Torn, And Gregory J. Hakim \\ University of Washington, Seattle, Washington
}

(Manuscript received 21 January 2005, in final form 6 July 2006)

\begin{abstract}
Ensemble Kalman filter (EnKF) data assimilation experiments are conducted on a limited-area domain over the Pacific Northwest region of the United States, using the Weather Research and Forecasting model. Idealized surface pressure, radiosoundings, and aircraft observations are assimilated every $6 \mathrm{~h}$ for a 7-day period in January 2004. The objectives here are to study the performance of the filter in constraining analysis errors with a relatively inhomogeneous, sparse-observation network and to explore the potential for such a network to serve as the basis for a real-time EnKF system dedicated to the Pacific Northwest region of the United States. When only a single observation type is assimilated, results show that the ensemble-mean analysis error and ensemble spread (standard deviation) are significantly reduced compared to a control ensemble without assimilation for both observed and unobserved variables. Analysis errors are smaller than background errors over nearly the entire domain when averaged over the 7-day period. Moreover, comparisons of background errors and observation increments at each assimilation step suggest that the flow-dependent filter corrections are accurate in both scale and amplitude. An illustrative example concerns a misspecified mesoscale 500-hPa short-wave trough moving along the British Columbia coast, which is corrected by surface pressure observations alone. The relative impact of each observation type upon different variables and vertical levels is also discussed.
\end{abstract}

\section{Introduction}

Research studies on the ensemble Kalman filter (EnKF) indicate that it is a useful data assimilation technique for atmospheric and oceanic applications (e.g., Evensen 1994; Houtekamer and Mitchell 1998; Hamill 2005). Many studies have addressed the basic properties of the EnKF in simplified models (e.g., Houtekamer and Mitchell 2001; Bishop et al. 2001; Whitaker and Hamill 2002; Anderson 2001). Recently, this work has expanded to applications in more complex NWP models using either synthetic observations (e.g., Mitchell et al. 2002; Snyder and Zhang 2003; Zhang et al. 2004) or real observations (e.g., Keppenne and Rienecker 2002; Houtekamer et al. 2005; Dowell et al. 2004; Whitaker et al. 2004). The goal of the present study is to assess the potential for a pseudo-operational EnKF to constrain errors on a limited-area domain for

Corresponding author address: Dr. Sébastien Dirren, Dept. of Atmospheric Sciences, University of Washington, Box 351640, Seattle, WA 98195-1640.

E-mail: sebastien.dirren@alumni.ethz.ch

DOI: 10.1175/MWR3358.1

(C) 2007 American Meteorological Society a location such as the Pacific Northwest region of the United States. This location presents a significant test for the robustness of data assimilation systems due to the presence of complex topography, land-ocean contrast, and a relatively inhomogeneous, sparse in situ observing network.

The EnKF extends the traditional Kalman filter (Kalman and Bucy 1961) using an ensemble of fully nonlinear forecasts to estimate a flow-dependent background-error covariance matrix. ${ }^{1}$ This matrix determines (i) the relative weighting of an observation relative to the background estimate (e.g., a 6-h forecast), (ii) the effect of an observation on nearby locations, and (iii) the relationships between different fields, for example the appropriate effect of a height observation on the wind field. In principle, the use of a flowdependent covariance matrix in the EnKF technique should yield analyses with smaller errors than those of methods that employ fixed covariance matrices, such as three-dimensional variational data assimilation (3DVAR).

\footnotetext{
${ }^{1}$ Here, we process observations serially, one at a time, and therefore the full covariance matrix is never explicitly calculated.
} 
Studies on EnKF techniques in complex models have addressed mainly the planetary to synoptic (e.g., Houtekamer et al. 2005; Keppenne and Rienecker 2002; Whitaker et al. 2004) and convective scales (e.g., Snyder and Zhang 2003; Zhang et al. 2004; Dowell et al. 2004), with fewer studies at the synoptic scale to mesoscale, which are of practical importance for both forecasting and analysis (verification) purposes. Data assimilation algorithms face different issues at these intermediate scales, such as significant deviations from (quasi-) geostrophy, structure across a wide range of spatial scales, and resolution of complex topography. For these conditions, the flow-dependent covariances produced by an EnKF system may depart significantly from a priori assumed covariance relationships, such as for 3DVAR.

An important issue for mesoscale domains in particular is the need for properly posed ensemble boundary conditions on limited-area domains. Whereas convective-scale case studies may avoid the use of ensemble boundary conditions over short time periods (Snyder and Zhang 2003; Dowell et al. 2004), this is not possible for longer time periods, since significant flow normal to the domain boundaries affects the domain interior. Torn et al. (2006) found that the use of deterministic boundary conditions in limited-area EnKFs produces "filter divergence" because the ensemble loses variance over time, thus giving less weight to observations. They proposed and tested several methods for generating ensemble boundary conditions, in particular when a global ensemble does not exist or is of the wrong size. One of the striking results from these idealized experiments was that despite larger errors near the boundaries, errors over the domain interior were similar to those for a comparable global experiment, even for methods that used alternative techniques to generate ensemble boundary conditions (i.e., in the case where a global ensemble does not exist for generating limited-area domain boundary conditions).

Here, we test one method proposed by Torn et al. (2006) by implementing an EnKF with the Weather Research and Forecasting model (WRF; e.g., Skamarock et al. 2005) for a period characterized by strong flow across the domain boundaries and significant weather features. Our objective is to assess how a limited-area domain EnKF performs at intermediate spatial scales in a region of complex topography with an inhomogeneous observation network. Moreover, the results from these experiments provide guidance on the necessary observations and parameter settings needed to realize the real-time EnKF system currently operating at the University of Washington (more information at http://www.atmos.washington.edu/ enkf). With this realistic goal in mind, the framework for this study is not entirely idealized, but rather intermediate in the sense that although observations are drawn from a truth simulation, the observation locations and errors apply to the real network. Furthermore, the boundary conditions use real operational short-term forecasts, which are available in real time, in contrast to analyses $6 \mathrm{~h}$ in the future, which are not.

The perfect model assumption is made here in order to rigorously quantify the performance of the filter. Observations are assimilated for an idealized, but realistic, network of surface pressure observations, radiosoundings, and aircraft measurements [e.g., the Aircraft Communications Addressing and Reporting System (ACARS)]. Filter performance is evaluated over the entire time period and at individual analysis times. The relative impact of each observation type upon different variables and vertical levels is also considered.

The outline of the paper is as follows. Section 2 describes the methodology of the study. Section 3 is devoted to a synoptic overview of the major flow characteristics during the 7-day period of interest. The average performance of the filter is then evaluated in section 4 for surface pressure observations, whereas the analysis increments at selected individual assimilation times are analyzed in section 5 . Results for different observation types are presented in section 6 . The last section provides a summary and a concluding discussion on the potential relevance of these results to the assimilation of real observations.

\section{Methodology}

We implement the EnKF with the WRF, a nonhydrostatic primitive equation, mesoscale model (Skamarock et al. 2005). The limited-area domain applies to the eastern North Pacific Ocean and adjacent region of western North America, and consists of a $102 \times 88$ horizontal grid with $45-\mathrm{km}$ grid spacing and 32 vertical levels. All model runs employ the Mellor-YamadaJanjić (Eta) turbulent kinetic energy (TKE) scheme, the Betts-Miller-Janjić convective scheme, and the WRF single-moment (WSM) three-class (water vapor, liquid water, and "simple" ice) microphysics scheme. The lateral boundary zone is five grid points wide with the outer boundary points specified by interpolated Global Forecasting System (GFS) values and the inner four boundary points by a linear combination of interpolated GFS values and WRF dynamics.

An ensemble square root filter (EnSRF) is employed, which does not require perturbed observations (Whitaker and Hamill 2002). Several experiments were performed to test the sensitivity of the results to the 
TABLE 1. Characteristics of each observation type. Note that vertical soundings sample observations from the following 10 levels: $925,850,700,600,500,400,300,200,150$, and $100 \mathrm{hPa}$.

\begin{tabular}{lccccc}
\hline \hline Observation type & No. of stations & No. of observations & Frequency $(\mathrm{h})$ & Min separation & Error \\
\hline Surface pressure & 108 & 108 & 6 & $4 \Delta x$ & $p_{\text {surf }}, 1 \mathrm{hPa}$ \\
Vertical soundings & 25 & 750 & 12 & $4 \Delta x$ & $u$ and $v, 1.5 \mathrm{~m} \mathrm{~s}{ }^{-1} ; \theta, 1 \mathrm{~K}$ \\
ACARS & $\sim 115$ & $\sim 345$ & 6 & $2 \Delta x, 25 \mathrm{hPa}$ & $u$ and $v, 1.5 \mathrm{~m} \mathrm{~s}$; $; \theta, 1 \mathrm{~K}$ \\
\hline
\end{tabular}

different tunable parameters available for an EnKF. This section presents and discusses the various parameter values that have been chosen in this study.

Several empirical tests indicated that 90 ensemble members was the minimum number needed to sufficiently resolve cross-variable covariances. Larger numbers of ensemble members did not seem to provide substantial additional benefit, which is consistent with previous studies (e.g., Whitaker et al. 2004; Mitchell et al. 2002). To partially eliminate spurious long-distance correlations, horizontal localization is applied using the compact correlation function of Gaspari and Cohn [(1999); Eq. (4.10)]. Trial-and-error testing with various localization radii yielded a useful value for this domain. The resulting radius of about $2000 \mathrm{~km}$ reflects a tradeoff between the desire to have a sufficiently short radius to avoid spurious far-field covariances and a sufficiently long radius to avoid shocks and imbalances (e.g., Houtekamer and Mitchell 2001; Hamill et al. 2001). Vertical localization is not applied here.

In several EnKF studies (Whitaker and Hamill 2002; Snyder and Zhang 2003; among others), covariance localization alone did not overcome the effect of undersampling, and covariance inflation was also employed. Here, ensemble perturbations are inflated by $6 \%$ at each assimilation time to prevent the ensemble from obtaining an overconfident estimate of the state (i.e., filter divergence). As suggested by other EnKF studies (e.g., Whitaker and Hamill 2002), this covariance inflation factor was chosen so that the time-averaged ratio of the RMS error of the ensemble mean analysis to the RMS error of each ensemble analysis member is 0.71 , as would be expected for a 90-member ensemble (Murphy 1988).

All experiments are performed under the perfectmodel assumption for a 7-day period in January 2004 with a 6-h data assimilation cycle. Truth is taken to be a solution of the WRF model starting with the GFS analysis at 1200 UTC 20 January 2004, which is integrated forward for 7 days with boundary conditions taken from 6-hourly GFS analyses. Having a truth run gives us the ability to quantify the performance of the system over the entire domain without having to consider model error or observation representativeness error.
Simulated observations consist of surface pressure (technically dry-air mass), radiosondes $(u, v$, and temperature, each $12 \mathrm{~h}$ ), and Aircraft Communications Addressing and Reporting System (ACARS) observations ( $u, v$, and temperature). A total of four experiments are conducted, with the first three corresponding to assimilating only one observation type, and the fourth experiment corresponding to assimilating all observations. Observation values are taken from the truth run with added uncorrelated Gaussian error; the error standard deviation for each observation type is provided in Table 1. Surface pressure observation locations represent a thinned version of the existing Automated Surface Observing System (ASOS) and fixed buoy network. The actual surface stations are placed on the nearest grid point with a minimum station spacing of four grid points. Radiosonde stations are also relocated to the nearest model grid point, and only mandatory-level data are assimilated (Table 1). ACARS observation locations are generated by taking the actual position of all such observations within $30 \mathrm{~min}$ of an assimilation time, and thinning such that the observations are at least two grid points and $25 \mathrm{hPa}$ apart. These procedures leads to 108 surface pressure stations, 25 vertical soundings, and an average of 115 ACARS locations per assimilation cycle.

The lateral boundary conditions for each ensemble member are perturbed using the "climatology time series" method described in Torn et al. (2006) and implemented as follows. Seven-day times series of archived GFS analyses (here from 1 September 2001 to 15 September 2002) are sampled starting at equally spaced times throughout the calendar year for each of the 90 ensemble members. For example, the time series for ensemble member one starts on 1 September 2001, the time series for ensemble member two starts on 5 September 2001, etc. The ensemble mean of these time series is removed and the resulting perturbations are scaled by a fixed constant (0.15) such that the RMS spread of the perturbations is equal to the RMS difference between 6-h GFS forecasts and GFS analyses valid at the same time. These scaled time series perturbations are added to the GFS 6-h forecast to get a unique boundary condition for each ensemble member at each analysis time. Here, we use a 6-h GFS forecast because 
a) 20 January 12 UTC

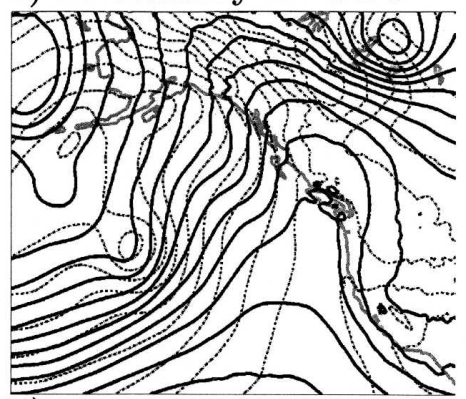

d) 23 January 12 UTC

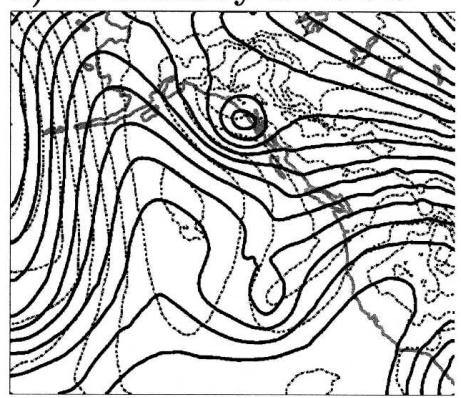

g) 26 January 12 UTC

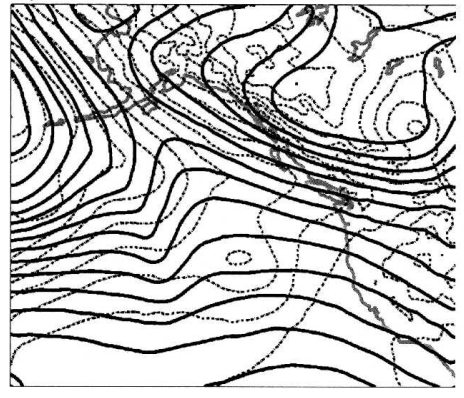

b) 21 January 12 UTC

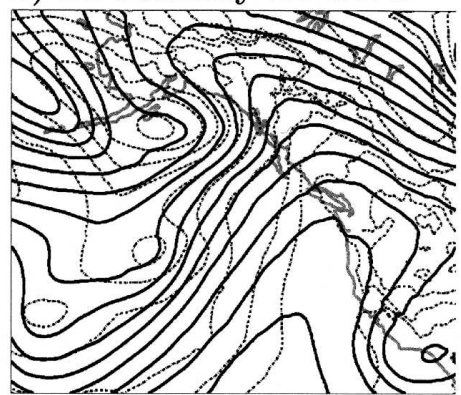

e) 24 January 12 UTC

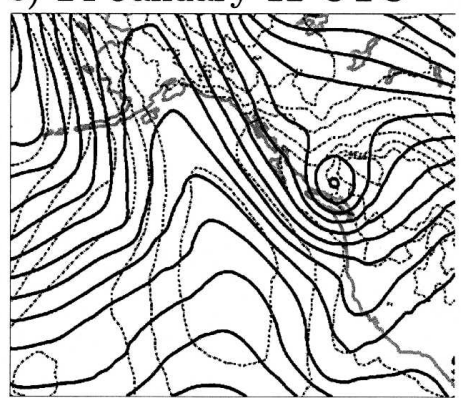

h) 27 January 12 UTC

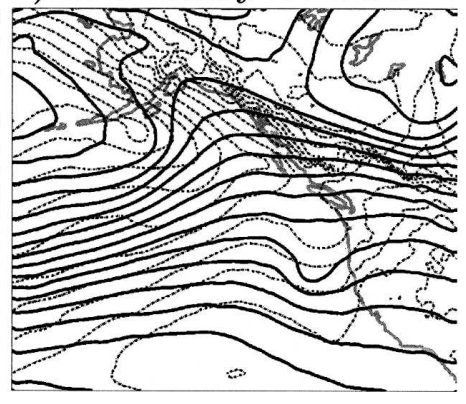

c) 22 January 12 UTC

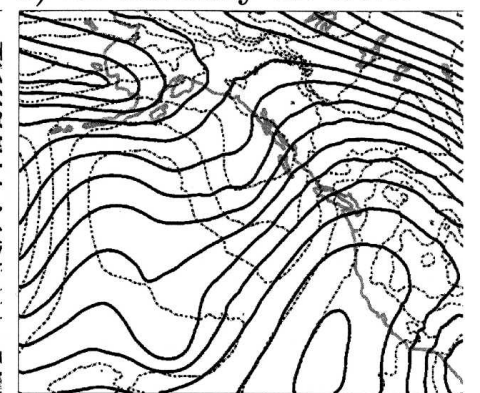

f) 25 January 12 UTC

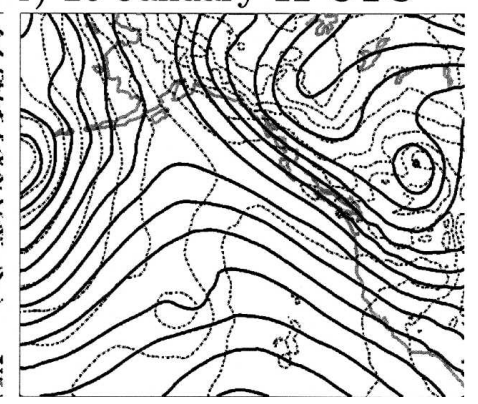

FIG. 1. Time evolution of the 500-hPa geopotential height (solid lines every $50 \mathrm{~m}$ ) and mean sea level pressure every $5 \mathrm{hPa}$ (dashed lines) in the truth run. the GFS analysis $6 \mathrm{~h}$ in the future is not available to a real-time data assimilation system. Moreover, using analyses as boundary conditions can lead to inappropriate weight being given to observations near the boundary since observations near the lateral boundaries will be assimilated twice: once in the global domain cycle and again in the limited-area domain cycle.

The initial ensemble is generated by a procedure similar to the "climatology time series" boundary method. Ninety equally spaced in time GFS analyses are drawn from the GFS analysis repository described above and the ensemble mean is removed from each. Next, the perturbations are multiplied by the same scaling factor determined for the boundary perturbations (0.15). Several tests indicated that increasing the scaling parameter by a larger amount led to imbalances and occasionally the model would crash. These ensemble perturbations are then added to a GFS forecast valid at 1200 UTC 20 January 2004 to get the initial ensemble. Several experiments were performed to identify which forecast hour would produce the best results. We found that when using a short-term forecast as the ensemble mean (i.e., 0- or 6-h forecast), the ensemble started to lose variance after a few assimilation times in a manner that was not consistent with the RMS errors in the ensemble mean; therefore, the ensemble became overconfident in its estimate of the state, and filter divergence occurred. Subsequent experiments showed that the best results were obtained when the ensemble mean of the initial ensemble was a longer-term forecast, here a 48-h forecast. Nevertheless, this calibration issue is tied strongly to our assumptions for the variance in the ensemble boundary conditions such that smaller variance than that used here may allow for using initial conditions with less error and spread.

\section{Overview of the development}

Figure 1 shows the 7-day time evolution of the 500$\mathrm{hPa}$ geopotential height and sea level pressure fields in 
the truth run. The evolution of the $500-\mathrm{hPa}$ pattern is characterized by a transition from a high-amplitude ridge over the eastern Pacific to more zonal flow. During the first 2 days, a large-scale ridge exists over the west coast of North America. Simultaneously, a cyclone (denoted by closed surface pressure isobars and a corresponding upper-level trough) moves northward along the west side of the ridge toward western Alaska (Figs. $1 \mathrm{a}$ and 1b). At 1200 UTC 22 January, anticyclogenesis over the Pacific elongates the upper-level trough located over western Alaska near the top of the ridge. A portion of this feature breaks free, creating a new shortwave trough that subsequently propagates southeastward along the west coast of North America (Figs. 1c and 1d). By 1200 UTC 24 January, the short-wave trough moves over southern British Columbia in northwesterly upper-level flow. During the next few days, the ridge breaks down as zonal flow becomes established over the eastern Pacific.

\section{Average performance of the filter}

To evaluate the filter's ability to constrain errors, we compare experiments where observations are assimilated with a control experiment without any assimilation. In this section we evaluate the filter performance in an averaged sense, by calculating both time- and space-averaged RMS errors of the ensemble mean, as well as the time-averaged ensemble standard deviation. Comparisons between background errors and observation increments for individual times are discussed in the next section.

Here, we define two different error diagnostics: the space-averaged RMS error of a variable $X$ (evaluated at a fixed vertical level) as a function of time,

$$
E_{t}^{X}=\sqrt{\frac{1}{N_{i}} \sum_{i=1}^{N_{i}}\left(\bar{X}_{t, i}-X_{t, i}^{\mathrm{tr}}\right)^{2}}
$$

and the time-averaged RMS error as a function of space,

$$
E_{i}^{X}=\sqrt{\frac{1}{N_{t}} \sum_{t=1}^{N_{t}}\left(\bar{X}_{t, i}-X_{t, i}^{\mathrm{tr}}\right)^{2}}
$$

where $\bar{X}_{t, i}$ is the ensemble mean at time $t$ and grid point $i, X_{t, i}^{\mathrm{tr}}$ is the corresponding truth value, and $N_{t}$ and $N_{i}$ correspond to the number of times and number of horizontal grid points, respectively.

Finally, the time-averaged analysis ensemble standard deviation (hereafter also called ensemble spread), $\sigma_{i}^{X}$, is defined by

$$
\sigma_{i}^{X}=\frac{1}{N_{t}} \sum_{t=1}^{N_{t}} \sqrt{\frac{1}{N_{e}-1} \sum_{j=1}^{N_{e}}\left(X_{t, i}^{j}-\bar{X}_{t, i}\right)^{2}},
$$

where $X_{t, i}^{j}$ is the value for ensemble member $j$ and $N_{e}$ represents the number of ensemble members.

\section{a. Space-averaged diagnostics}

Figure 2 shows the space-averaged RMS errors of the ensemble-mean analysis as well as the RMS ensemble spread, as a function of time. All fields in the control experiment (Fig. 2, left panels) exhibit increasing ensemble spread with time due to the lack of observational constraint. Interestingly, the ensemble-mean error actually decreases initially for a period of time. This result is due to the fact that the initial error is relatively large and the ensemble-mean boundary condition is set to the GFS 6-h forecast, which generally has smaller errors. A decrease in the ratio of the ensemble-mean error to the ensemble spread indicates that an ensemble is not properly calibrated relative to the true state (e.g., Anderson 2001). For comparison, the spread and RMS error calculation are repeated by replacing the true state with ensemble member 90 , yielding an 89 -member "perfect ensemble" (Fig. 3). In this case, the ensemblemean RMS error and ensemble spread in the dry-air mass field grow consistently, although the ensemble spread is initially larger. This initially larger spread is introduced so that observations are weighted more heavily than the background in the data assimilation experiment.

When surface pressure observations are assimilated, the ensemble-mean analysis errors and ensemble spread decrease toward stochastic equilibrium and are, after 2 days, at smaller values relative to the control case (Fig. 2, right panels). This result suggests that the 108 inhomogeneously distributed surface pressure observations efficiently constrain errors for this domain, even though no observations are assimilated over half of the domain. In particular the domain-average RMS analysis error for surface pressure is similar to or smaller than the 1-hPa observation error after 2 days, whereas corrections to nonobserved variables also lead to significant reductions of both error and ensemble spread (Figs. 2c-h).

\section{b. Time-averaged diagnostics}

Figure 4 gives the spatial distribution of the timeaveraged ensemble-mean RMS analysis error for the dry air mass and the time-averaged ensemble spread. In the control experiment (left panels), persistent errors with large uncertainty are located along the west coast of Canada and over the eastern Pacific Ocean, coinci- 
a) $\mathbf{E}_{t}^{\mathrm{p}_{\text {surf }}}$ Control

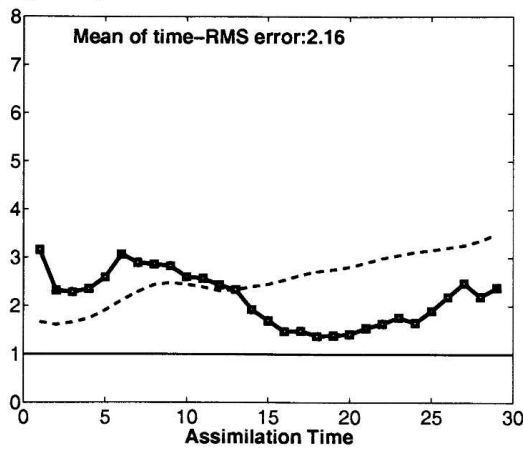

c) $\mathrm{E}_{\mathrm{t}}^{\mathrm{z} 500}$ Control

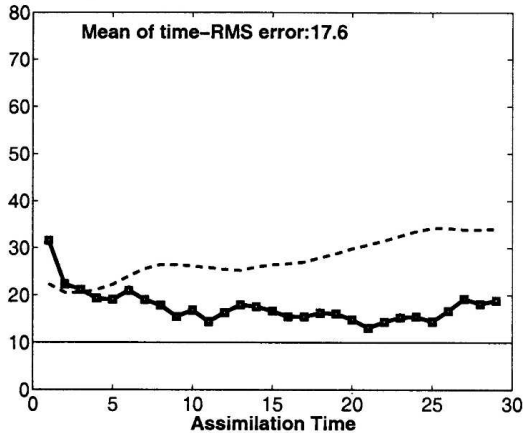

e) $\mathrm{E}_{\mathrm{t}}^{\theta_{\mathrm{500}}}$ Control

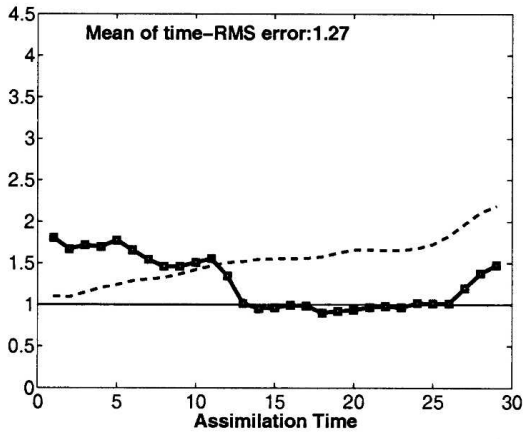

g) $\mathrm{E}_{\mathrm{t}}^{\mathrm{vel}_{\text {surf }}}$ Control

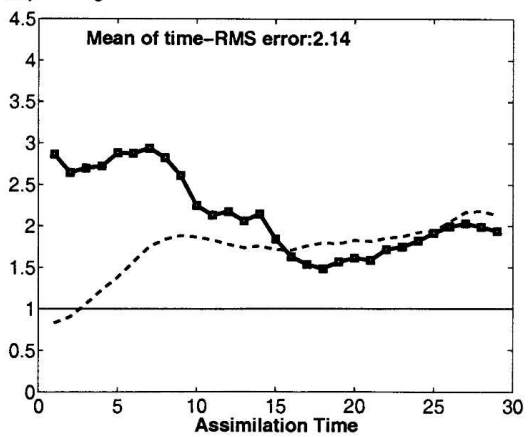

b) $\mathbf{E}_{t}^{p_{\text {surf }}}$ with observations

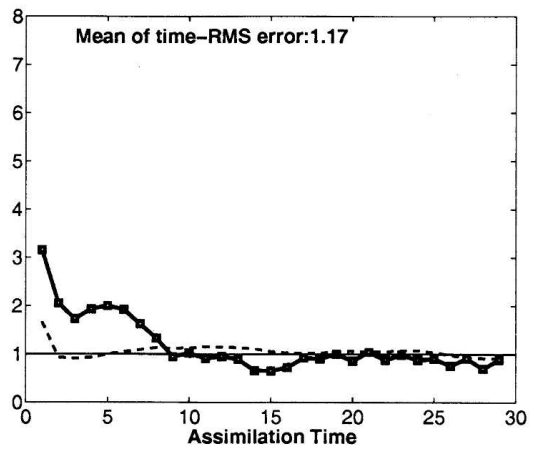

d) $E_{t}^{z_{500}}$ with observations

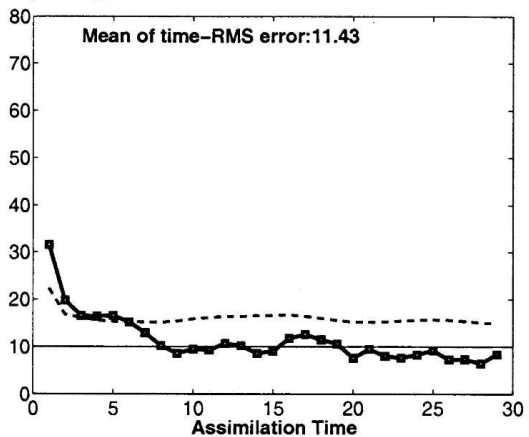

f) $\mathbf{E}_{\mathbf{t}}^{\theta_{500}}$ with observations

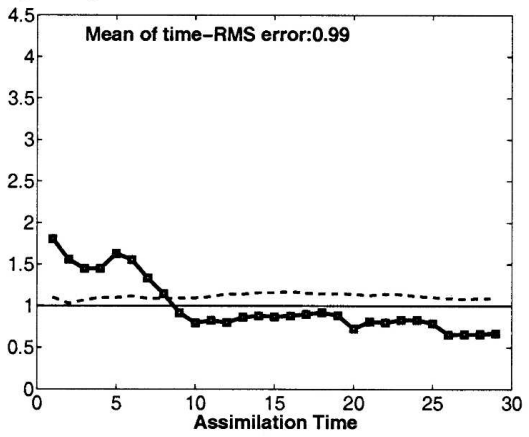

h) $\mathrm{E}_{\mathrm{t}}^{\mathrm{vel}_{\text {surf }}}$ with observations

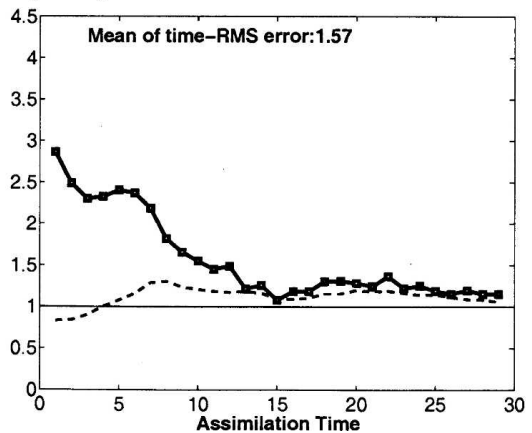

FIG. 2. RMS errors $\left(E_{t}^{X}\right)$ as a function of time for the ensemble-mean analysis (heavy solid line with circles) as well as the RMS ensemble spread (dashed line), for the (left) noassimilation control experiment and (right) experiment with surface pressure observations. Corresponding time-mean RMS values are indicated in each panel. The fields considered are (a), (b) surface pressure (hPa), (c), (d) 500-hPa geopotential height (m), (e), (f) 500-hPa potential temperature $(\mathrm{K})$, and $(\mathrm{g})$, (h) surface wind speed $\left(\mathrm{m} \mathrm{s}^{-1}\right)$. The thin solid line in (a) and (b) represents observation error, and thin lines are drawn in other panels for reference. 


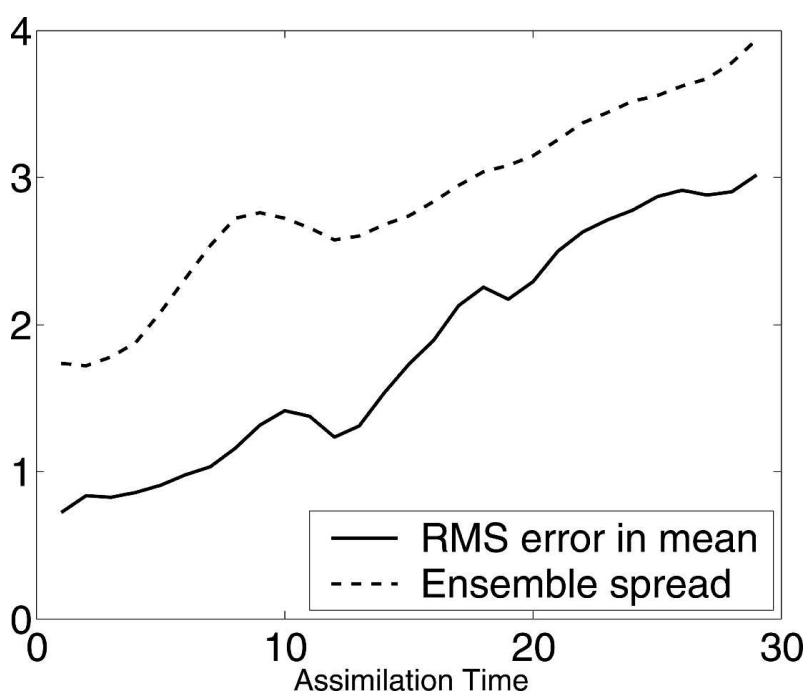

FIG. 3. Dry-air mass ensemble-mean RMS errors (solid line) and ensemble spread (dashed line) as a function of time for the no-assimilation control experiment when truth is assumed to be ensemble member 90 and the statistics are computed with respect to the other 89 ensemble members $(\mathrm{hPa})$.

dent with the areas of highest variance about the 7-day time mean (not shown).

In contrast, Fig. 4 (right panels) shows how the assimilation of surface pressure observations decreases both the error and ensemble variance in places near observations. Error and spread are smaller than observation error (i.e., $\leq 1 \mathrm{hPa}$ ) where the observation network is relatively dense, but they are similar to the control experiment south of the Gulf of Alaska where surface pressure observations are not available. Domain-averaged RMS analysis error and ensemble spread decrease by $50 \%$ and $64 \%$, respectively, relative to the control case.

The assimilation of surface pressure observations also reduces the error in unobserved variables. Figure 5 focuses on both 500-hPa geopotential height and surface wind speed, but similar results are obtained for both horizontal components of the wind at these levels (not shown). Similar to Fig. 4, errors are reduced in areas of dense observations. RMS errors (over space and time) and ensemble spread in the 500-hPa height field are reduced by $32 \%$ and $42 \%$, respectively, compared to the control experiment. These results suggest that surface pressure observations drawn from the existing inhomogeneous ASOS network may constrain analysis errors not only at the surface but also in the middle and lower troposphere, consistent with results found by Whitaker et al. (2004). We note that the region of persistent errors in the northeast corner of the domain probably results from the fact that the flow during the period of interest is from the northwest, leaving little time for appropriate flow-dependent covariances to develop in this location.

For the surface wind speed field (Figs. 5e-h), the structure of time-averaged RMS errors and ensemble spread differ from those for the mass field in that the wind speed field has errors with smaller spatial scales, although errors are still generally larger over the ocean. The increased power in the smaller spatial scales is attributed to the fact that the wind is approximately the derivative of the pressure field, which weights smaller scales. Despite the presence of several areas of persistent errors, mainly in data-sparse regions, the domainaveraged RMS ensemble-mean analysis errors and ensemble spread are reduced by $26 \%$ and $35 \%$, respectively, relative to the control experiment.

\section{c. Background analysis}

To evaluate the performance of the data assimilation step, we consider the difference between the timeaveraged RMS error of the ensemble-mean background and the analysis fields:

$$
\Delta E_{i}^{X}=\left(E_{i}^{X}\right)_{\mathrm{back}}-\left(E_{i}^{X}\right)_{\mathrm{anal}} .
$$

Similarly, we define the difference in the background and analysis ensemble spread by

$$
\Delta \sigma_{i}^{X}=\left(\sigma_{i}^{X}\right)_{\text {back }}-\left(\sigma_{i}^{X}\right)_{\text {anal }} .
$$

Positive values in these quantities indicate that, on average, the ensemble-mean error and ensemble spread are smaller for the analysis than for the background. Figure 6 shows that this is in fact the case over nearly the entire domain for the 500-hPa height and surface pressure fields. Note that the analysis errors are actually slightly larger than the background for the $500-\mathrm{hPa}$ height field over small areas near the Gulf of Alaska and British Columbia. The largest average error reductions are near the west coast of North America, collocated with much of the significant weather during this period, suggesting that observations along the coast are important in correcting short-term forecast errors in this region.

Domain averages of $\Delta E_{i}^{X}$ and $\Delta \sigma_{i}^{X}$ reveal the largest analysis-error reduction for the surface pressure fields ( $\approx 40 \%$ ), with smaller reductions for unobserved fields ( $15 \%$ for $500-\mathrm{hPa}$ height and $5 \%$ for surface wind speed). An important consideration in this comparison regards the fact that observation assimilation leads not only to better analyses but also to better forecasts, which is apparent from $\left(E_{i}^{X}\right)_{\text {back }}<\left(E_{i}^{X}\right)_{\text {control }}$ for all fields (Figs. 4 and 5). For example, while surface windspeed-averaged RMS analysis errors are only 5.5\% 


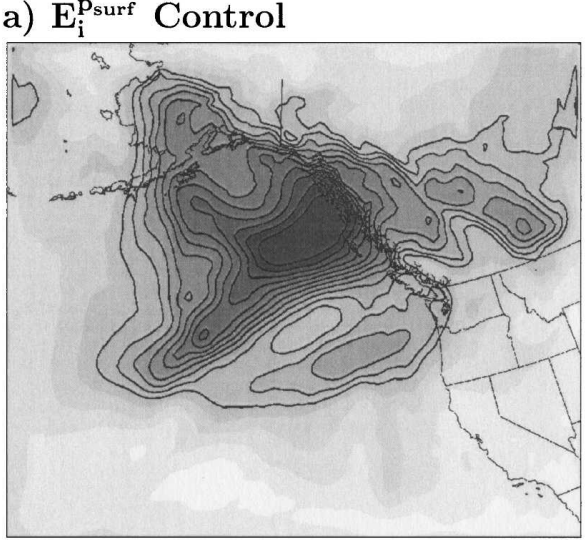

Mean: 2.02

c) Mean $\sigma_{\mathrm{i}}^{\text {purf }}$ Control

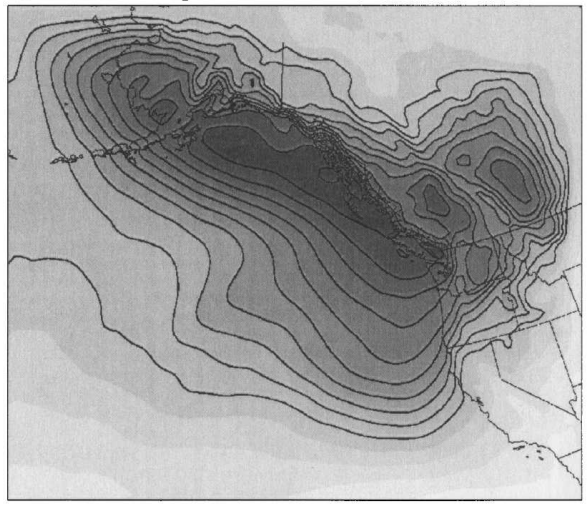

Mean: 2.42 b) $E_{i}^{\text {psurf }}$ with observations
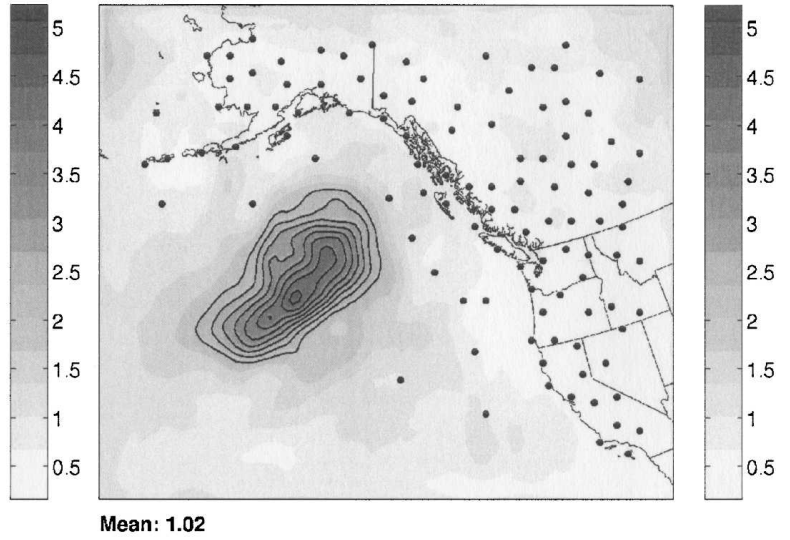

d) Mean $\sigma_{\mathbf{i}}^{\mathbf{p}_{\text {surf }}}$ with observations
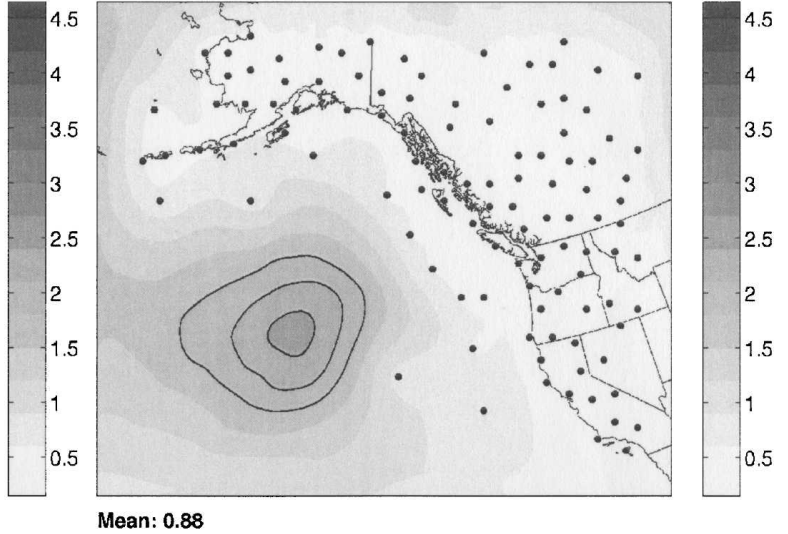

FIG. 4. Horizontal distribution of time-averaged RMS errors ( $\left.E_{i}^{p \text { surf }}\right)$ of the (top) ensemble mean analysis and (bottom) time-averaged std $\operatorname{dev}\left(\sigma_{i}^{p \text { surf }}\right)$ of the analysis ensemble for surface pressure over the 7-day period in (left) the control experiment and (right) the experiment where surface pressure observations are assimilated. Domainaveraged RMS values are displayed below each figure (units: hPa).

smaller than the averaged background errors, the RMS background errors are $22 \%$ smaller than in the control experiment.

\section{Instantaneous performance of the filter}

The previous section analyzed the averaged performance of the limited-area EnKF in both space and time. Here, we consider instantaneous filter corrections by comparing background errors and analysis increments at individual assimilation times to reveal how the assimilation of surface pressure observations adjusts the background fields. As an illustrative example, Fig. 7 shows background errors (colors) and the analysis increment defined as the difference between analysis and background fields (negative values dashed) of four different quantities at 1800 UTC 24 January. Ideally, the analysis increments would be the negative value of the background error at each grid point.
Analysis increments for surface pressure are accurate in both scale and amplitude when compared with background errors (Fig. 7a). More precisely, the large positive background errors centered over British Columbia are collocated with large negative analysis increments, and negative background errors near Alaska are collocated with positive analysis increments. Two localized regions have analysis increments of the wrong sign at this time: one over the Aleutian Islands and another over the ocean, near the center of the domain. The first region can be related to the prescribed backgrounderror covariances on the lateral boundary, and the second is due to the lack of observations. Domainaveraged RMS pressure errors are reduced by $26 \%$ during this analysis cycle. As an alternative metric, we consider RMS errors averaged near each observation location. Surface stations with analysis errors smaller (larger) than background errors averaged within a 450$\mathrm{km}$ radius of the stations are shown in green (red) 
a) $\mathrm{E}_{\mathrm{i}}^{\mathrm{Z} 500}$ Control

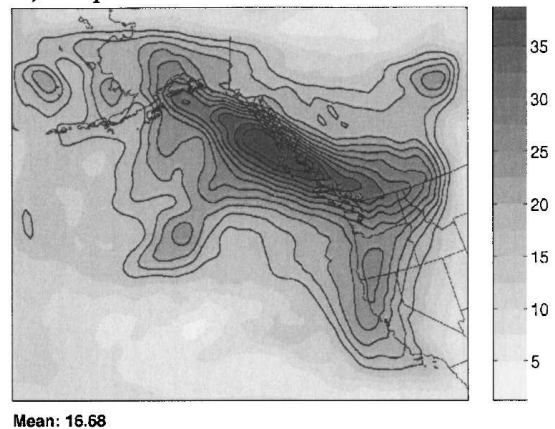

c) Mean $\sigma_{i}^{\mathrm{z} 500}$ Control

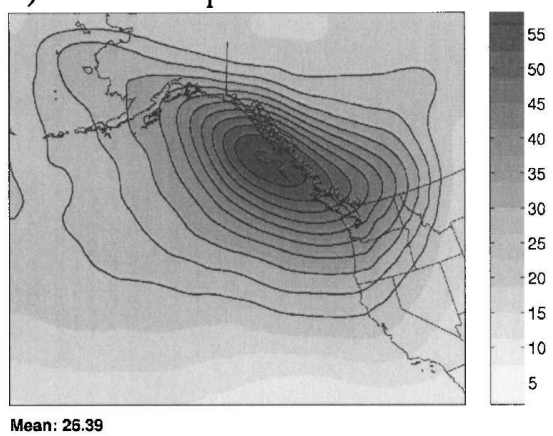

e) $\mathrm{E}_{\mathrm{i}}^{\mathrm{vel}} \mathrm{l}_{\text {surf }}$ Control

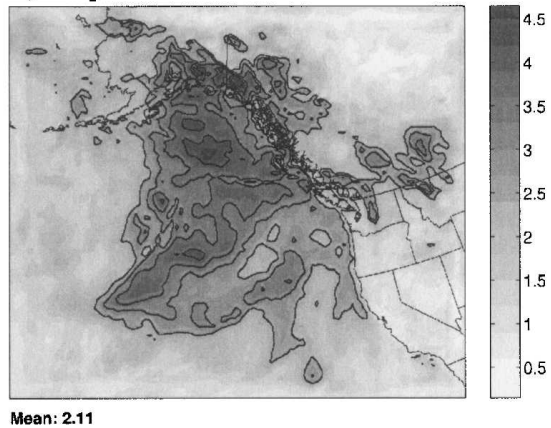

g) Mean $\sigma_{i}^{\text {vel }_{\text {surf }}}$ Control

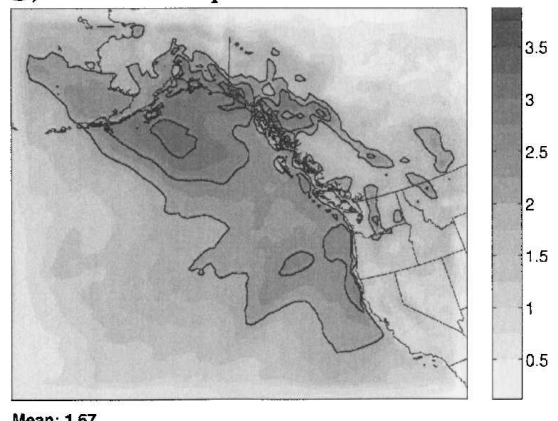

b) $E_{i}^{z_{500}}$ with observations

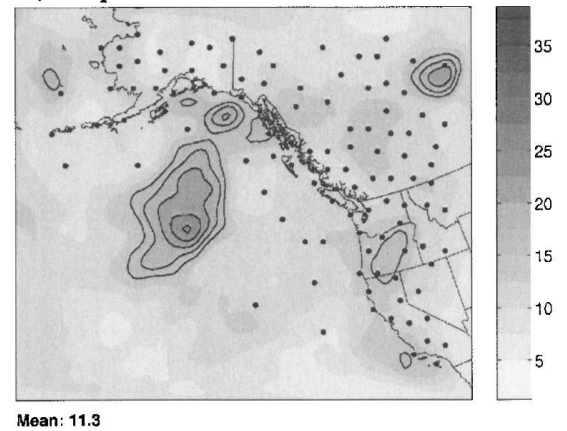

d) Mean $\sigma_{i}^{\text {z500 }}$ with observations

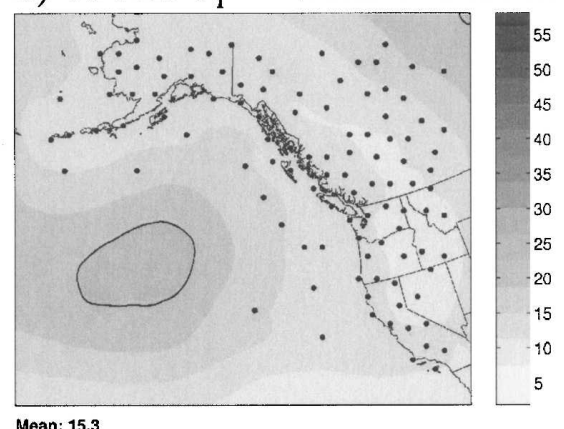

f) $\mathrm{E}_{\mathrm{i}}^{\mathrm{vel}_{\text {surf }}}$ with observations

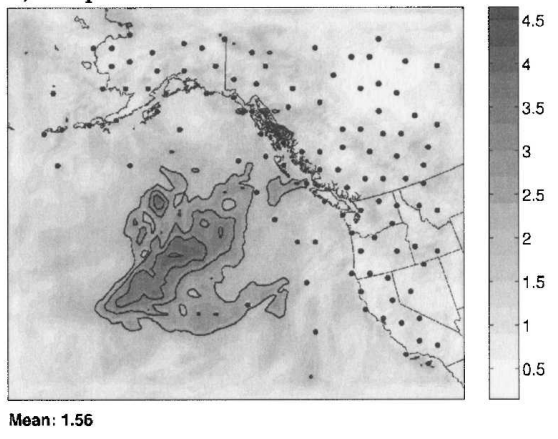

h) Mean $\sigma_{i}^{\text {vel }_{\text {surf }}}$ with observations

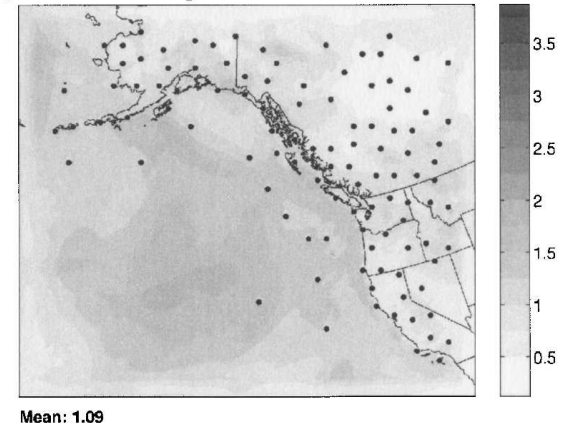

FIG. 5. As in Fig. 4 but for the (a)-(d) 500-hPa geopotential height (m) and (e)-(h) surface wind speed $\left(\mathrm{m} \mathrm{s}^{-1}\right)$. 
a) $\Delta E_{i}^{p_{\text {surf }}}$

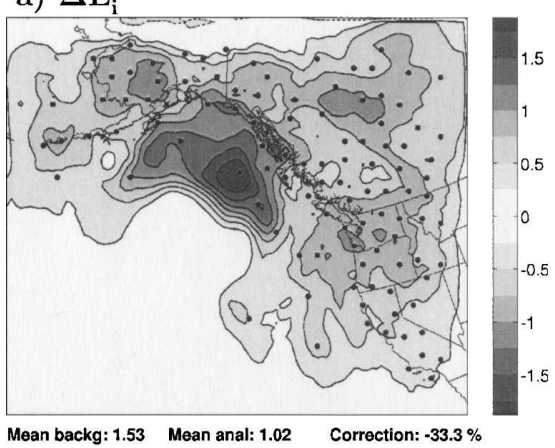

c) $\Delta E_{i}^{Z_{500}}$

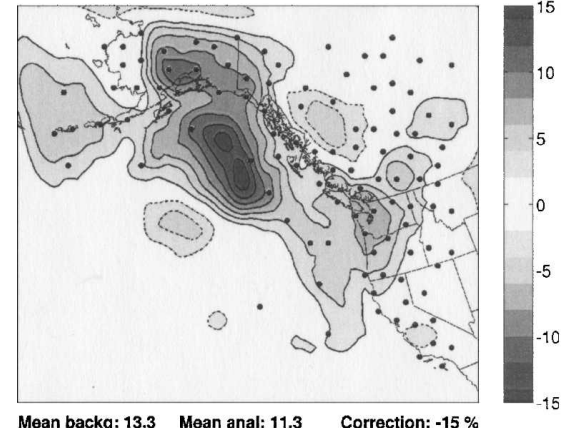

e) $\Delta E_{i}^{v^{\text {el }} \text { surf }}$

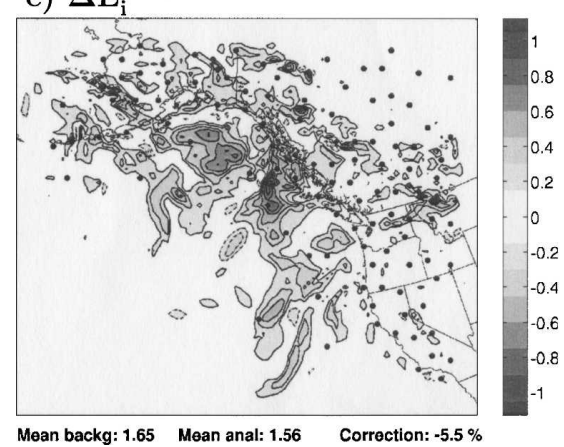

b) $\Delta \sigma_{i}^{p_{\text {surf }}}$

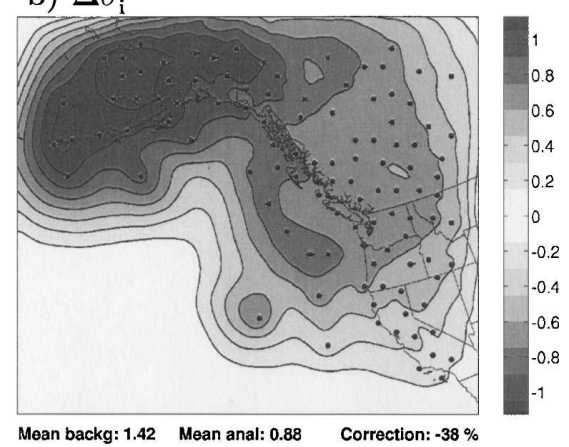

d) $\Delta \sigma_{i}^{\mathrm{z} 500}$

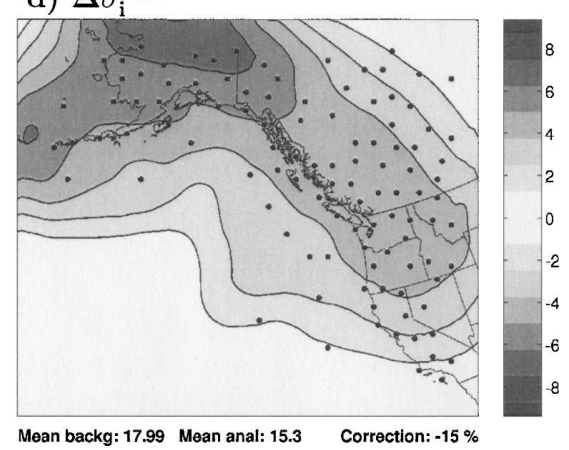

f) $\Delta \sigma_{i}^{\text {vel }}$ surf

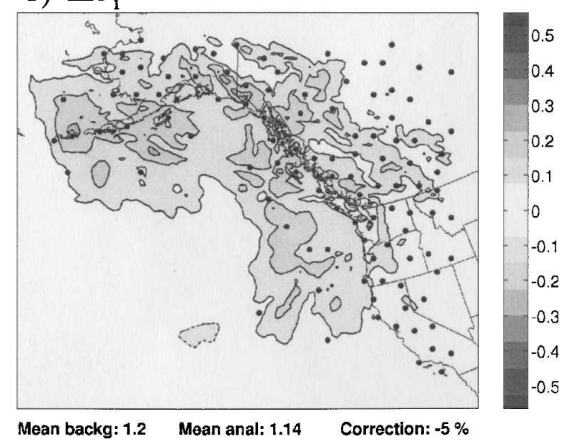

FIG. 6. Difference of time-averaged (left) RMS errors [Eq. (2)] and (right) std devs [Eq. (3)] between the background and the analysis fields. Positive values indicate that observation assimilation systematically reduces errors, or ensemble spread. Also shown are the corresponding averages in RMS errors and the reduction between the analysis and the background (\%).

circles. This reveals that $94 \%$ of the stations have analysis errors smaller than the background errors (Fig. 7).

Analysis increments are also accurate for unobserved fields, as shown in Figs. 7b-d. In general, regions characterized by large (in scale and amplitude) background errors typically experience accurate corrections. This result is particularly evident for the $500-\mathrm{hPa}$ geopotential height field. In contrast, for $500-\mathrm{hPa}$ temperature, although there exist two regions where large background errors are corrected, on a domain-averaged basis there is a slight increase in the RMS analysis errors compared to the background errors. To infer the im- pact of surface pressure observations on the temperature field, Fig. 8a shows the time-averaged vertical correlation between surface pressure observations and the temperature at each mandatory level from 1000 to 100 $\mathrm{hPa}$ for the last 4 days of our experiment. As would be expected for surface observations, the correlations are largest near the surface and decrease with pressure to near zero at $500 \mathrm{hPa}$ and above. This figure is in qualitative agreement with other studies that have explored the correlation between the surface pressure and the tropospheric temperature (e.g., Rabier et al. 1998, their Fig 8; Derber and Bouttier 1999, their Fig. 8). More- 
a) Back. error and innovation for $p_{\text {surf }}$

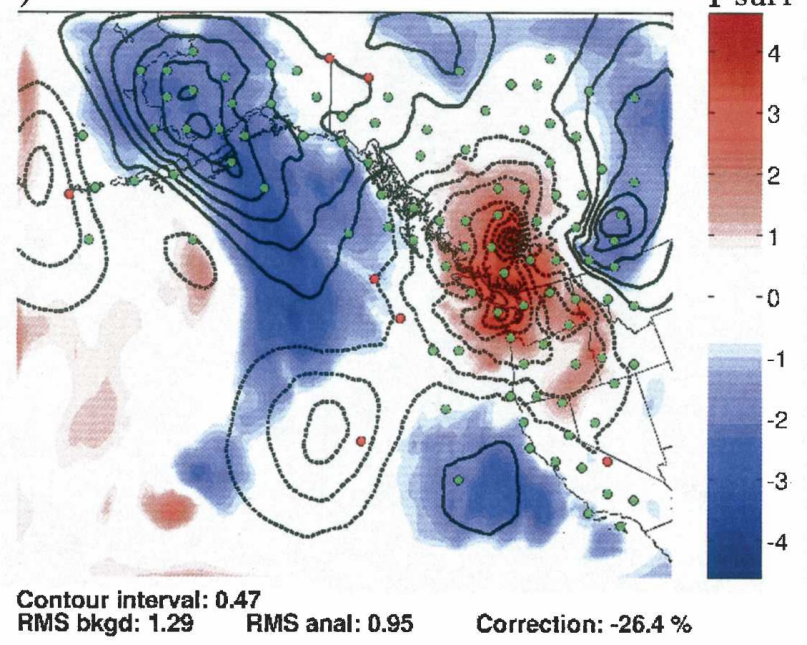

b) Back. error and innovation for $z_{500}$

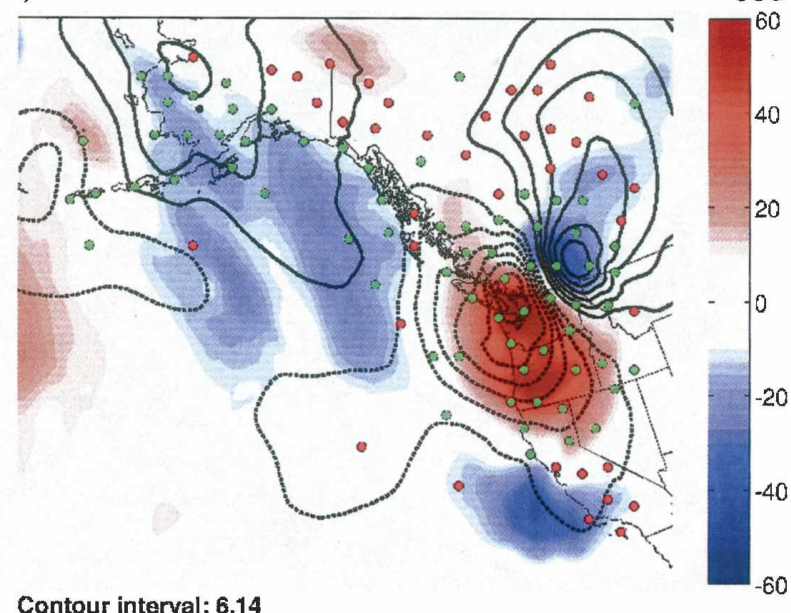

Contour interval: 6.14

RMS bkgd: 14.56 RMS anal: 12.18 Correction: $-16.3 \%$

c) Back. error and innovation for vel surf $_{\text {d) }}$ (

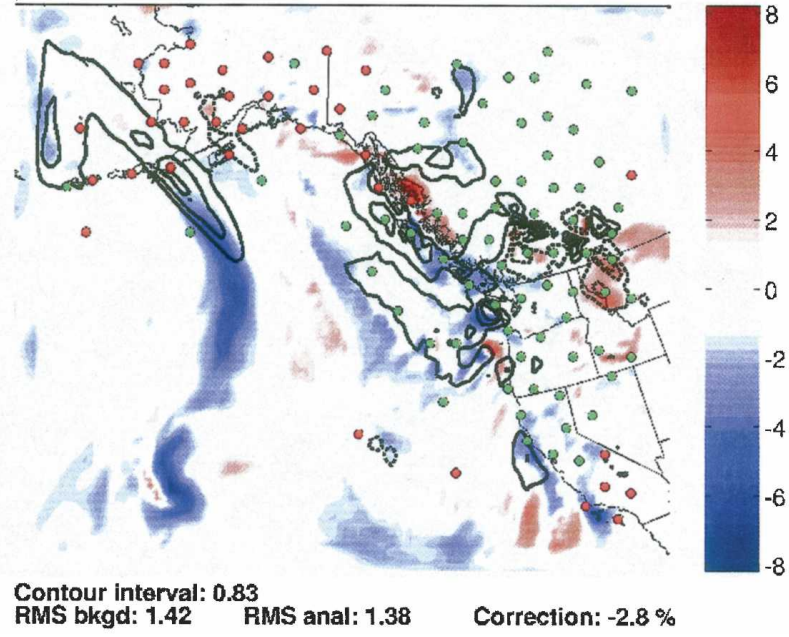

d) Back. error and innovation for $\theta_{500}$

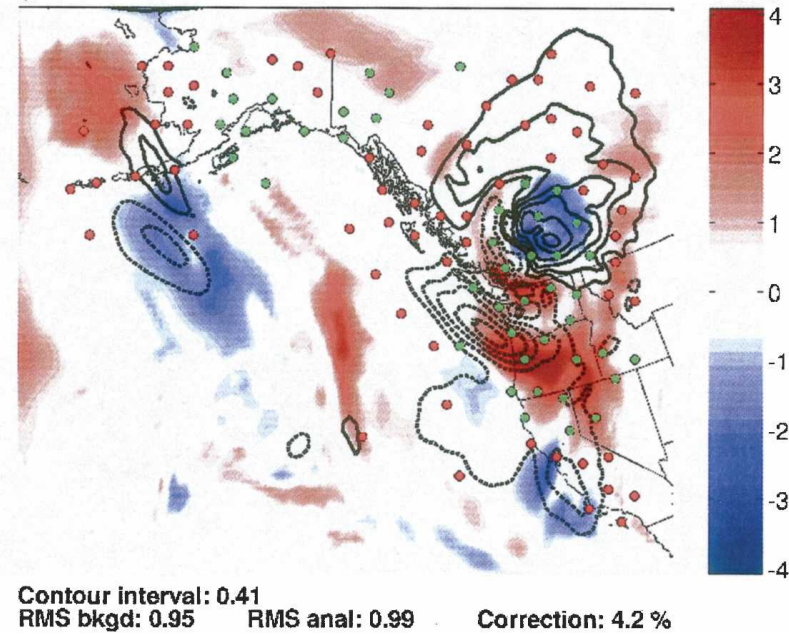

FIG. 7. Instantaneous background errors (colored, $\bar{X}_{i}^{\text {back }}-X_{i}^{\text {tr }}$ ) and analysis increments (contours, $\bar{X}_{i}^{\text {anal }}-\bar{X}_{i}^{\text {back }}$ ) for (a) surface pressure (hPa), (b) 500-hPa geopotential height (m), (c) surface wind speed ( $\mathrm{m} \mathrm{s}^{-1}$ ), and (d) 500-hPa potential temperature (K) at 1800 UTC 24 Jan 2004. Domain-averaged RMS errors and the associated reduction in RMS error (\%) are shown below each panel. Stations characterized by smaller RMS error in the analysis as compared to the background within $450 \mathrm{~km}$ of the observation location are colored green, and red otherwise.

over, Fig. $8 \mathrm{~b}$ also shows that the mean vertical correlation between surface pressure observations and geopotential height are large throughout the lower troposphere, but decrease with height. Since the height and mass fields are related by the hydrostatic balance, this correlation pattern is not unexpected. Unlike temperature, there appears to be a nonzero correlation between surface pressure and height at $500 \mathrm{hPa}$; thus, on average, assimilating surface pressure observations should have an impact on the 500-hPa height field.

Recall from the synoptic discussion in section 3 that a short-wave trough moves southeastward along the west coast of North America (Fig. 1). This trough is associated with large errors in the control experiment (Fig. 9, left panel). Errors associated with this feature are reduced by the assimilation of only surface pressure observations in this experiment (Fig. 9, right panel). Specifically, after three 6-h analysis cycles, both the scale and magnitude of the errors are greatly reduced compared to both the control simulation (Fig. 9, left panels) and to the background (Fig. 9, right panels).

To better illustrate how a surface pressure observation alters the 500-hPa height field for the times in Fig. 9, we present the Kalman gain in Fig. 10 for the surface pressure observations located closest to the $500-\mathrm{hPa}$ 

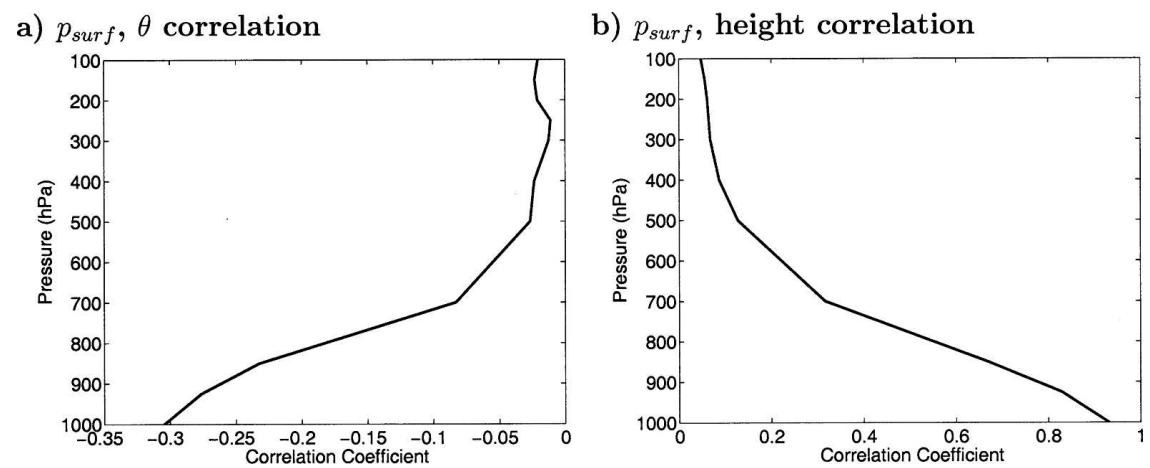

FIG. 8. Mean vertical correlation of each surface pressure observation location with (a) temperature and (b) geopotential height at each mandatory level $(1000-100 \mathrm{hPa})$ over the last 4 days of this experiment.

height trough. For comparison, the gain for the surface pressure observation using the WRF 3DVAR covariance model is also shown (Barker et al. 2004). Large differences exist between the EnKF gain (Figs. 10a-c) as compared to the WRF 3DVAR gain (Fig. 10d). Whereas surface pressure observations assimilated with ensemble covariances shift the trough either upstream or downstream depending on the sign of the innovation, the WRF 3DVAR covariances change the amplitude of the trough, but not its position. Noting the strong correspondence between the shape of the innovations in Fig. 9 and the gain values in Fig. 10 suggests that the surface pressure observations near the trough have the greatest impact.

Finally, Fig. 11 shows a scatterplot of the background errors versus the negative of the analysis increment at each of the observation locations for all assimilation times. The high correlation coefficients for surface pressure and 500-hPa geopotential height indicate that the analysis increment results presented in Figs. 7 and 9 are systematic during the entire period. The smaller correlation coefficient for surface wind speed can be related to the structure of the cross-variable covariances between surface pressure and wind speed, which may be expected to be maximized a few grid points from a surface pressure observation location since these variables are related approximately by a horizontal derivative. The small correlation coefficient in Fig. 11c indicates that the correlations between surface pressure and midtropospheric temperature are weak, as discussed above.

\section{Different types of observations}

The results of the previous sections suggest that 108 surface pressure observations are sufficient to reduce both the ensemble-mean analysis error and the en- semble spread of different variables through a deep layer of the troposphere. On the other hand, we have also shown that the midtropospheric temperature field is not as strongly affected by surface pressure observations due to small covariances. We consider now the impact of observations of winds and temperature at various vertical levels as would come from radiosoundings and ACARS data. The aim here is first to simulate aspects of a real-time data assimilation system based on conventional observations for the region of interest, and second to discuss the relative impact of each type of observations. We will also investigate the corrections of background errors in the midtropospheric temperature.

Figure 12 shows the difference between the timeaveraged RMS errors of the ensemble-mean background and the analysis $500-\mathrm{hPa}$ potential temperature [Eq. (4)] and the difference in the ensemble spread [Eq. (5)], based upon the assimilation of surface pressure (Figs. 12a and 12b), vertical soundings (Figs. 12c and 12d), and ACARS observations (Figs. 12e and 12f). Recall from above that surface pressure observations have a relatively small impact on analysis errors and ensemble spread for the midtropospheric temperature (Figs. 12a and 12b); however, errors in this field decrease considerably when radiosonde (Figs. 12c and 12d) and ACARS (Figs. 12e and 12f) observations are assimilated. Even though the locations of ACARS observations are time dependent, a direct comparison of the error reduction (Figs. 12e and 12f) at ACARS observation locations (Fig. 13) indicates a good correlation between the analysis increments and dense regions of ACARS observations (predominantly distributed near major airports).

A comparison of the RMS errors associated with assimilating each of the different observation types supports and extends the previous results. Tables 2 and 3 show, respectively, the mean (over time and space) 
a) 23 Jan 06 UTC (Control)

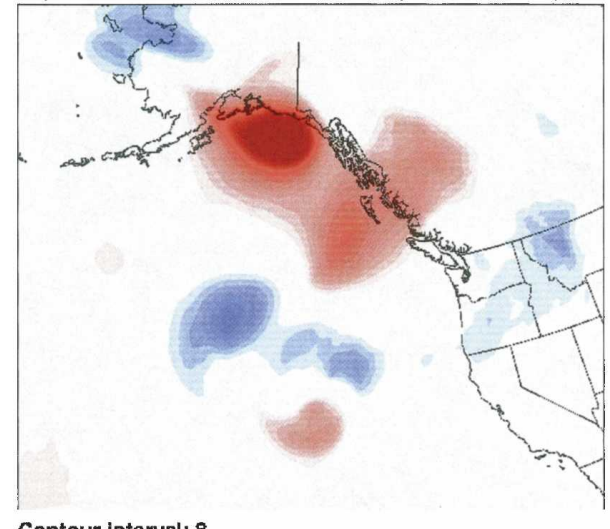

Contour interval: 8

RMS bkgd: 17.41 RMS anal: 17.41 Correction: $0 \%$

c) 23 Jan 12 UTC (Control)

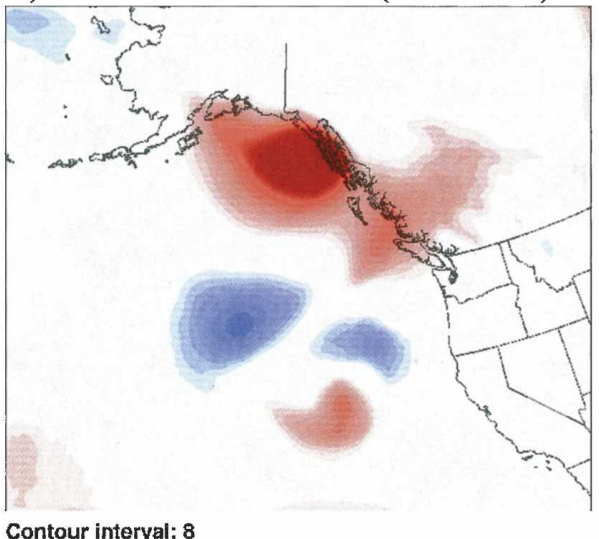

Contour interval: 8
RMS bkgd: 19.04

e) 23 Jan 18 UTC (Control)

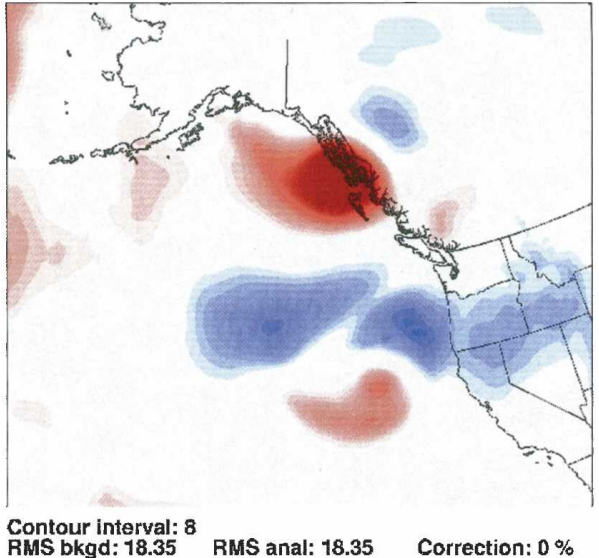

b) 23 Jan 06 UTC (with p surf $_{\text {obs) }}$

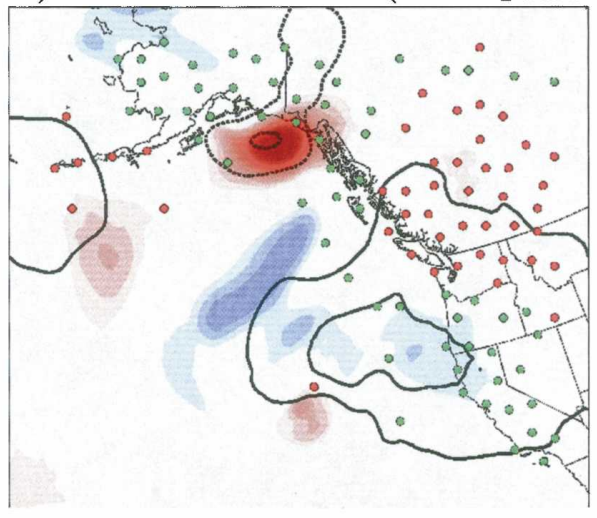

Contour interval: 8
RMS bkgd: 12.39 RMS anal: 11.42 Correction: $-7.8 \%$

d) 23 Jan 12 UTC (with $p_{\text {surf }}$ obs)

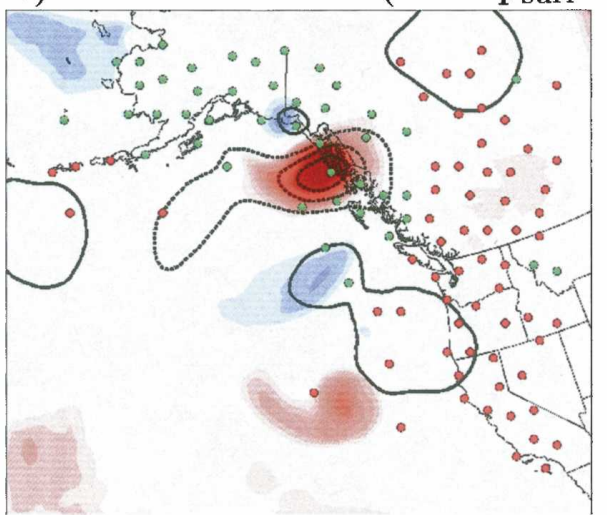

Contour interval: 8
RMS bkgd: 11.98 RMS anal: 10.42 Correction: $-13 \%$

f) $23 \mathrm{Jan} 18 \mathrm{UTC}$ (with $\mathrm{p}_{\text {surf }}$ obs)

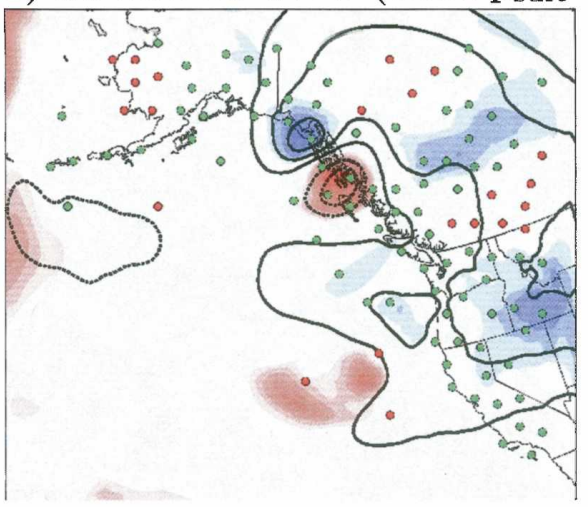

Contour interval: 8
RMS bkgd: 10.12 RMS anal: 8.25 Correction: $-18.5 \%$

8 유 $\circ$ ํำ 운

FIG. 9. As in Fig. 7 but for the 500-hPa geopotential height for (left) the control experiment and (right) the assimilation experiment with surface pressure observations. 
a) 23 Jan 06 UTC

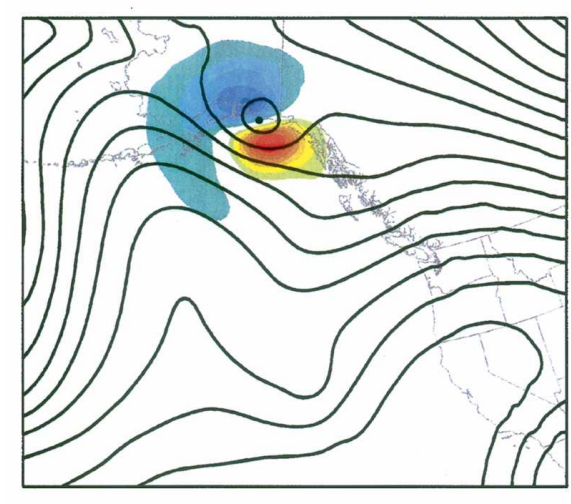

c) 23 Jan 18 UTC

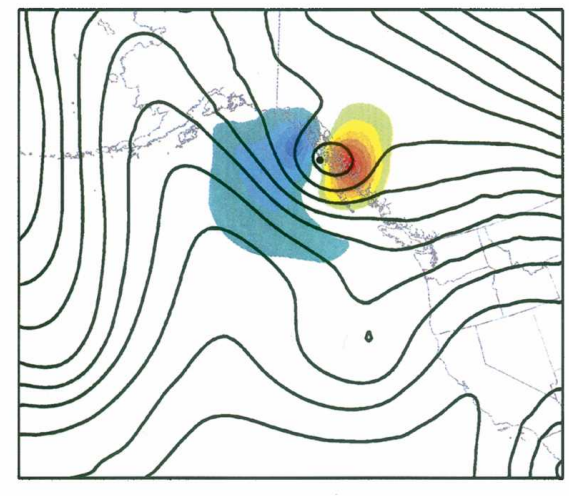

b) 23 Jan 12 UTC
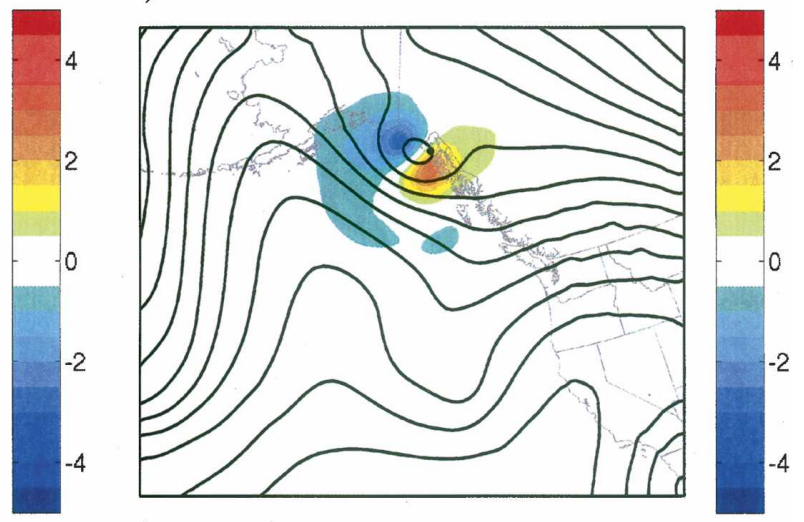

d) 23 Jan 12 UTC WRF 3D-VAR
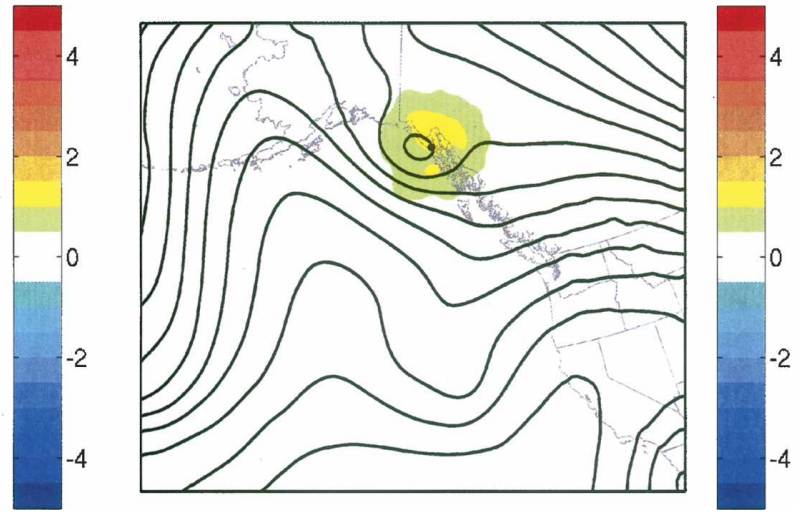

FIG. 10. Kalman gain in 500-hPa height for a single surface pressure observation taken at the boldface dot (color shading; $\mathrm{m} \mathrm{hPa}^{-1}$ ) as calculated from the ensemble at (a) 0600, (b) 1200, and (c) 1800 UTC 23 Jan. (d) The gain as calculated from the WRF 3DVAR system at 1200 UTC 23 Jan. Thin solid lines show the ensemble-mean 500-hPa geopotential height every $60 \mathrm{~m}$.

RMS analysis error and analysis ensemble spread for the assimilation of each observation type. It is apparent that the assimilation of a single observation type results in smaller analysis errors and ensemble spread as compared to the control experiment for both observed and unobserved variables. Furthermore, the assimilation of surface pressure observations leads to smaller errors and variance in the lower troposphere, whereas soundings and ACARS are more useful for reducing errors in the midtroposphere. Interestingly, these results also suggest that errors in midtropospheric geopotential height are effectively reduced by surface pressure observations alone. A quantitative intercomparison between different observation types is difficult since each observation type resolves different variables, levels, and locations. To partly overcome this inhomogeneity, RMS errors and standard deviation have been averaged near the observation sites alone by the method described above (values in parentheses in Tables 2 and 3 ). As might be expected, the smallest RMS errors are realized when assimilating all observation types, whereas the relative influence of individual observation types depends on the field and on the vertical level considered.

\section{Discussion and outlook}

In this study we have tested the performance of a limited-area EnKF data assimilation system that resolves subsynoptic scales on a domain with rich topography, inhomogeneous observation density, and substantial flow normal to the lateral boundaries. Three different types of synthetic observations have been assimilated over a 7-day period characterized by significant weather features. Single observation-type experiments show that both ensemble-mean error and ensemble spread are significantly reduced for both observed and unobserved variables when compared to an ensemble control integration where no observations are assimilated. 
a) Back. error vs -innovation for $\mathrm{p}_{\text {surf }}$

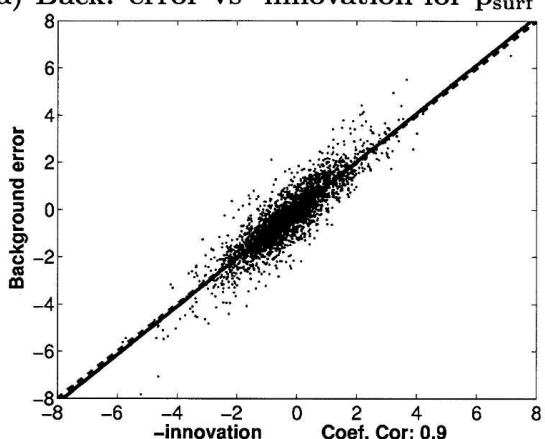

c) Back. error vs -innovation for $\theta_{500}$

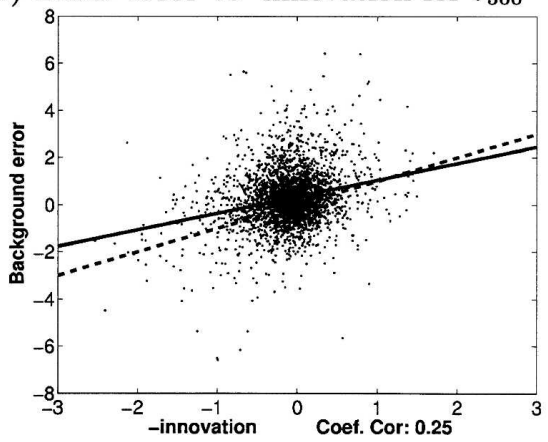

b) Back. error vs -innovation for $\mathrm{z}_{500}$

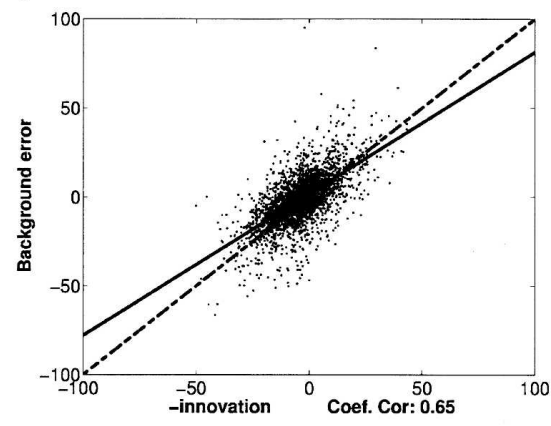

d) Back. error vs -innovation for vel $_{\text {surf }}$

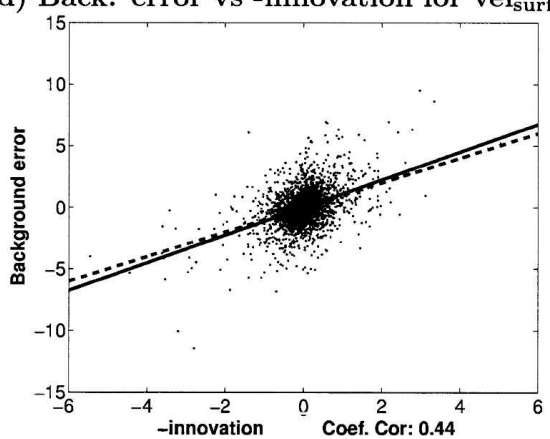

FIG. 11. Background error $\left(\bar{X}^{\text {back }}-X^{\text {truth }}, y\right.$-axis $)$ vs the negative of the analysis increments ( $\bar{X}^{\text {back }}-\bar{X}^{\text {anal }}, x$-axis) at the observation locations for (a) surface pressure (hPa), (b) $500-\mathrm{hPa}$ geopotential height (m), (c) 500-hPa potential temperature (K), and (d) surface wind speed $\left(\mathrm{m} \mathrm{s}^{-1}\right)$ when assimilating surface pressure observations. The linear regression and the ideal correction are given by the solid line and dashed lines, respectively. Corresponding correlation coefficients are indicated below each figure.

Analysis errors are systematically smaller than background errors when averaged over the entire domain, over the entire time period, and near an observation location; that is, the assimilation step reduces errors. A comparison of background errors and analysis increments at individual assimilation steps suggests that the analysis increments are accurate in both scale and amplitude, especially for the observed fields. Interestingly, we find that the assimilation of surface pressure observations is effective at constraining errors from the surface up through the midtroposphere despite the use of an inhomogeneous observing network and a relatively small number of observations. Finally, whereas a quantitative comparison of the relative impact of each observation type depends strongly on the spatial distribution of observations, the results suggest that, not surprisingly, the largest error reduction is achieved when all observation types considered here are assimilated.

These promising results indicate that the "climatology time series" method proposed by Torn et al. (2006) generates useful ensemble boundary perturbations when a global ensemble is not available (in particular for a real-time assimilation system). These results also offer a glimpse into how a data assimilation system at these subsynoptic scales may perform given the current conventional observation network of surface stations, radiosondes, and aircraft (ACARS) data. However, the above results represent an upper bound on the EnKF performance when assimilating real observations since these experiments are based on the perfect model assumption. When assimilating real data, issues concerning model error and observation representativeness may affect the performance of the filter. With the goal of assimilating real observations in mind, we offer comments on each observation type below.

Surface pressure observations appear to be effective in constraining both lower-tropospheric fields and geopotential height up through at least the middle troposphere. The existing surface pressure network is relatively dense over land and, although sparse, extends over the ocean in the form of buoys and ship reports. A significant issue with surface observations concerns representativeness due to differences between model topography and the actual station elevation, especially near complex terrain where stations are often located within unresolved valleys. To use these observations, 
a) Surface pres. obs.

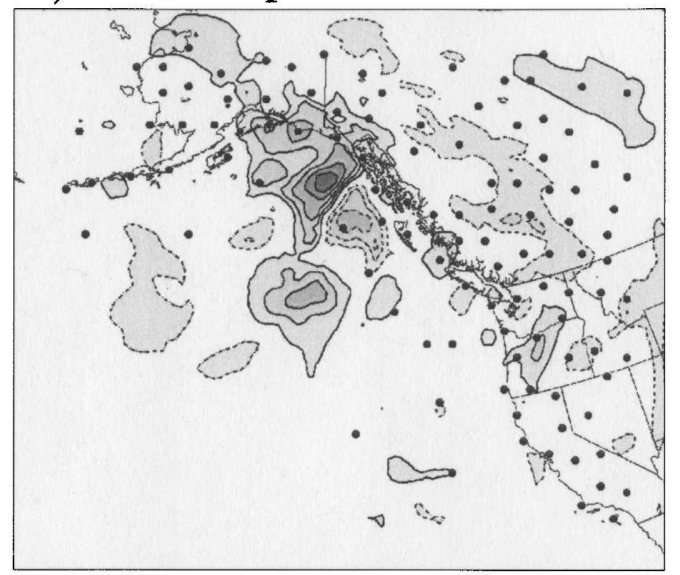

Mean backg: 1.03 Mean anal: 1.03

Correction: $0 \%$

c) Soundings obs.

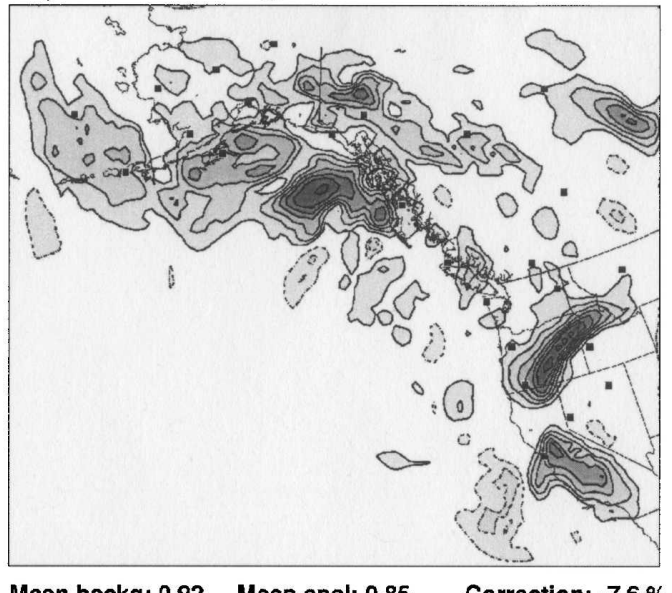

e) ACARS obs.

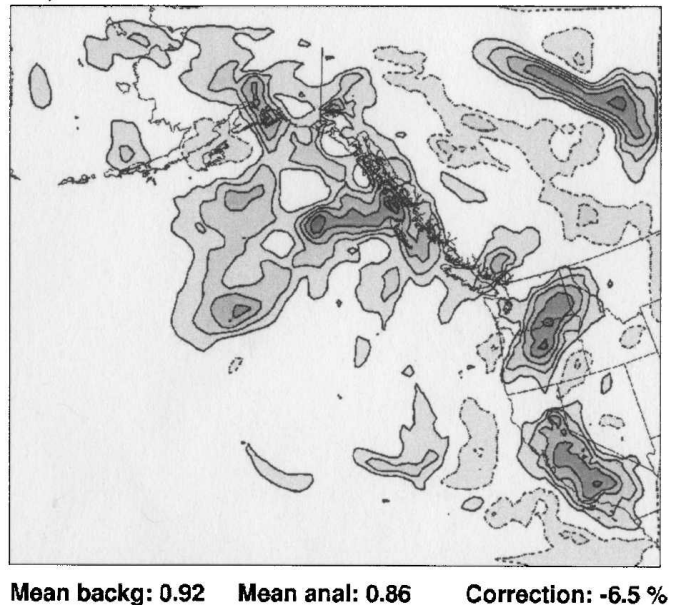

b) Surface pres. obs.
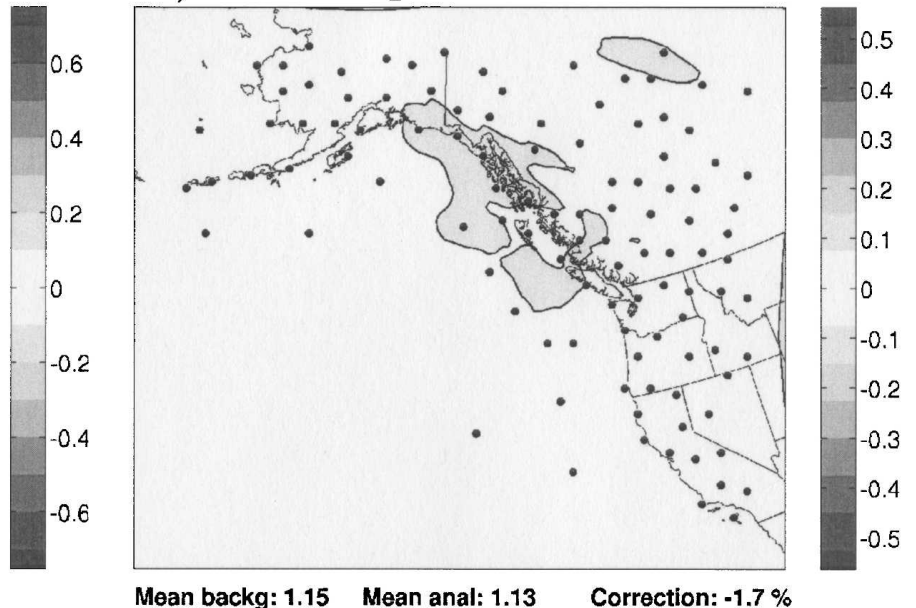

d) Soundings obs.
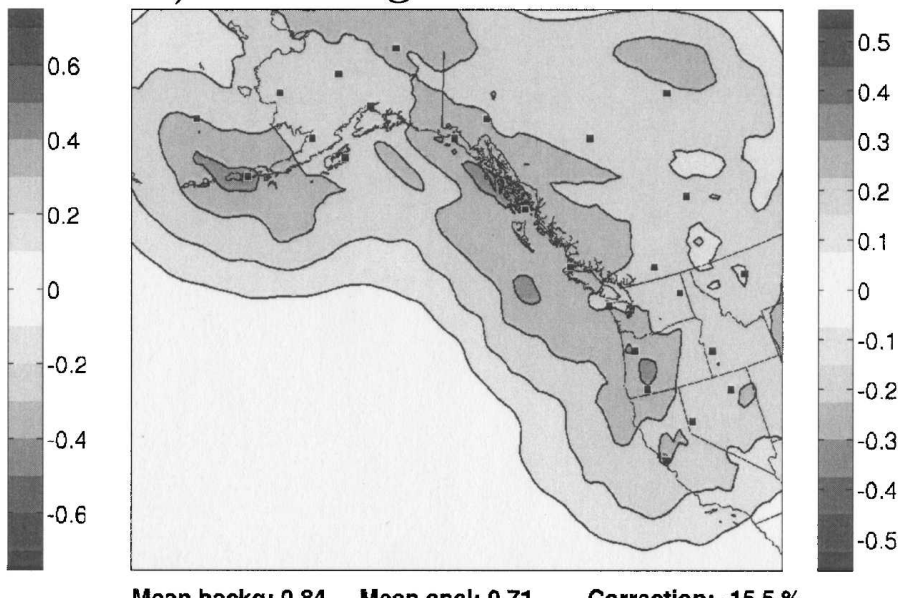

Mean backg: 0.84 Mean anal: 0.71 Correction: $\mathbf{- 1 5 . 5 \%}$ f) ACARS obs.
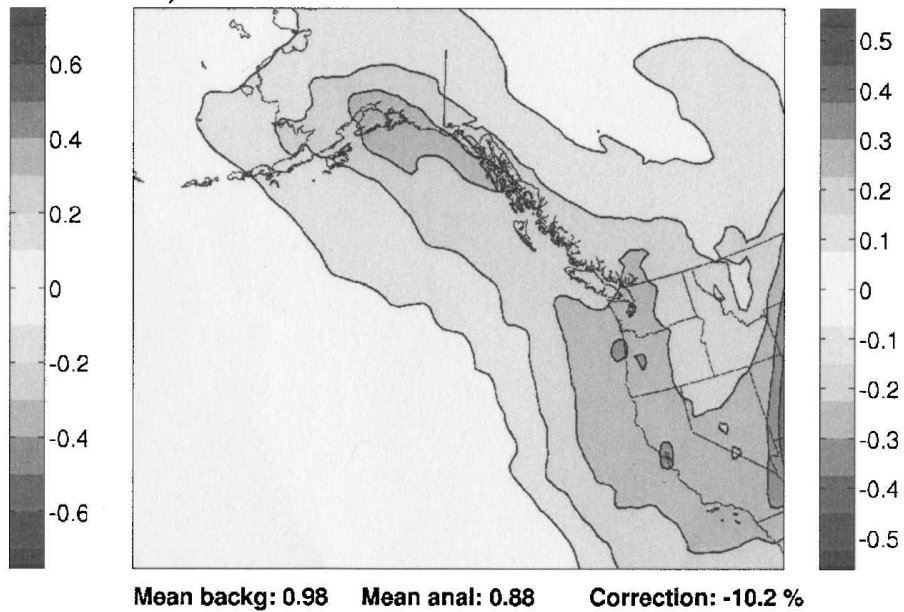

FIG. 12. Difference of time-averaged (left) RMS errors [Eq. (4)] and (right) ensemble spread [Eq. (5)] between the background and analysis 500-hPa potential temperature based upon the assimilation of (top) surface pressure, (middle) vertical soundings, and (bottom) ACARS observations. Positive values denote areas where the filter systematically reduces errors, or spread, from the background values. The corresponding domain-averaged RMS error and the reduction in RMS error in the analysis relative to the background (\%) are shown below each panel. 


\section{Distribution of ACARS observations}

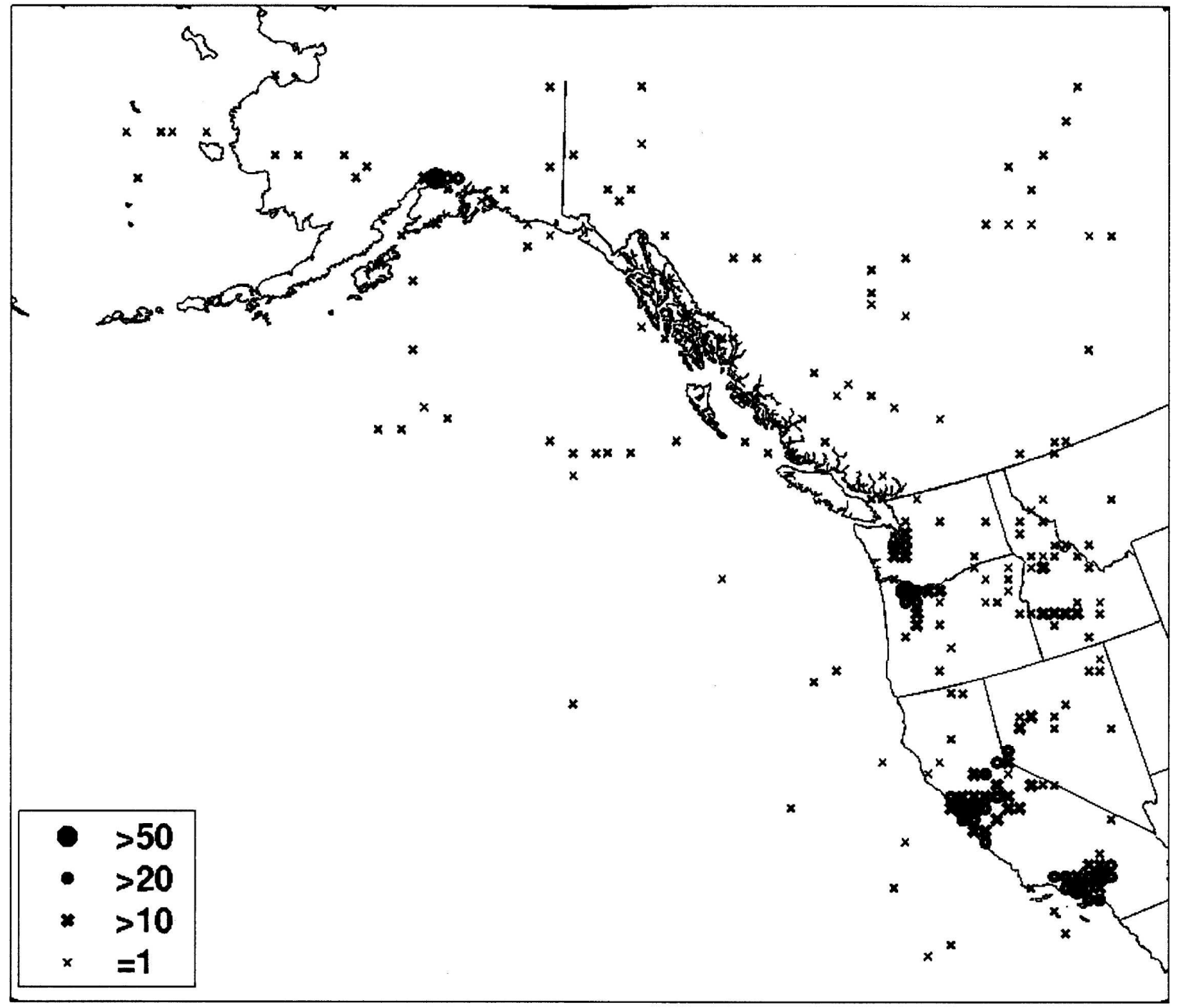

\section{Number of obs:3239 (lower:542; middle:1152; upper:1545)}

FIG. 13. Horizontal distribution of ACARS observations during the 7-day period. Low-, mid-, and upper-level observations are defined by the $800-1050-, 400-800-$, and $50-400-\mathrm{hPa}$ layers, respectively.

TABLE 2. Ensemble-mean RMS errors over time and space for each observation-type experiment. Values in parenthesis indicate averaged RMS errors averaged within $450 \mathrm{~km}$ of the observation locations. Velocity is abbreviated as vel.

\begin{tabular}{llllll}
\hline \hline \multicolumn{1}{c}{ Mean $E^{q}(i)$} & $p_{\text {surf }}(\mathrm{hPa})$ & $z_{500}(\mathrm{~m})$ & $\theta_{500}(\mathrm{~K})$ & $u_{500}\left(\mathrm{~m} \mathrm{~s}^{-1}\right)$ & $\mathrm{vel}_{\text {surf }}\left(\mathrm{m} \mathrm{s}^{-1}\right)$ \\
\hline Control & 2.02 & 16.68 & 1.25 & 4.12 & 2.11 \\
Surface pressure observations & $1.02(0.58)$ & $1.51(1.26)$ & $1.03(1.17)$ & $3.20(3.41)$ & $1.56(1.22)$ \\
Soundings observations & $1.51(1.26)$ & $12.37(11.72)$ & $0.85(0.82)$ & $2.96(2.25)$ & $1.69(1.14)$ \\
ACARS observations & $1.65(1.55)$ & $13.69(13.79)$ & $0.86(0.69)$ & $2.86(1.99)$ & $1.76(0.97)$ \\
All observations & $1.03(0.64)$ & $9.63(7.95)$ & $0.78(0.73)$ & $2.61(1.94)$ & $1.50(0.98)$ \\
\hline
\end{tabular}


TABLE 3. As in Table 2 but for the average std dev of the analysis ensemble $\left[\sigma^{q}(i)\right]$. Velocity is abbreviated as vel.

\begin{tabular}{llllll}
\hline \hline \multicolumn{1}{c}{ Mean $\sigma^{q}(i)$} & $p_{\text {surf }}(\mathrm{hPa})$ & $z_{500}(\mathrm{~m})$ & $\theta_{500}(\mathrm{~K})$ & $u_{500}\left(\mathrm{~m} \mathrm{~s}^{-1}\right)$ & $\mathrm{vel}_{\text {surf }}\left(\mathrm{m} \mathrm{s}^{-1}\right)$ \\
\hline Control & 2.42 & 26.39 & 1.47 & 4.07 & 1.77 \\
Surface pressure observations & $0.88(0.46)$ & $15.30(12.79)$ & $1.13(1.09)$ & $2.73(2.63)$ & $1.14(0.85)$ \\
Soundings observations & $1.28(1.05)$ & $13.64(10.41)$ & $0.71(0.42)$ & $2.02(1.14)$ & $1.03(0.54)$ \\
ACARS observations & $1.47(0.74)$ & $15.12(7.11)$ & $0.88(0.36)$ & $2.30(0.96)$ & $1.26(0.51)$ \\
All observations & $0.75(0.33)$ & $8.83(4.06)$ & $0.61(0.32)$ & $1.75(0.89)$ & $0.92(0.42)$ \\
\hline
\end{tabular}

quality control measures will be necessary so that observations are only assimilated for stations where the model topography and station elevation are similar.

Although vertical soundings provide good vertical resolution at one location, the existing radiosonde network is particularly sparse in the horizontal (e.g., only 25 stations over the domain considered here). Unlike surface stations, observation representativeness is less of an issue, especially above the surface.

ACARS observations may be a particularly useful source of information in regions where radiosonde and surface pressure observations are sparse, especially over the Pacific Ocean (from transcontinental flights). However, ACARS observations are frequently over land in the form of airport approaches and takeoffs and may, therefore, be subject to representativeness errors, especially for valley airports. Finally, whereas observations of the previous types are available only at prescribed time intervals, ACARS data are available continuously. For fixed assimilation intervals, a thinning procedure may be necessary to filter the observations. We note that, in general, the EnKF is not constrained to fixed assimilation intervals (synchronous observations), although high performance in the asynchronous case requires tighter coupling between the model and the EnKF assimilation algorithm. ${ }^{2}$

Although our results show that analysis errors are effectively constrained over land, additional observation types are necessary to achieve similar performance over the ocean. One candidate is cloud-track wind observations (Nieman et al. 1997). Although these winds have larger observation errors when compared to soundings and ACARS, the observation density is typically much higher and could be a good source of wind information over the open ocean, especially outside the major flight tracks. However, Bormann et al. (2003) showed that errors in cloud wind data can be highly

\footnotetext{
${ }^{2}$ The weak coupling between the model and the assimilation algorithm is usually regarded as a positive attribute of the EnKF. Tighter coupling in the case of asynchronous observations is required so that model fields are accessible in random access memory (fast), avoiding the need to frequently read and write ensemble data to disk (slow).
}

correlated, thus reducing their usefulness. Satellite radiances are heavily used by many operational centers at synoptic scales, and therefore it may be useful to consider these observations in future experiments.

A final consideration for the application of EnKF techniques to limited-area domains concerns the specification of ensemble boundary conditions. Although the method used here to generate ensemble boundary conditions around global model analyses works well at $45-\mathrm{km}$ resolution, it may not perform as well at higher resolution. Moreover, higher spatial resolution may require more frequent boundary updates, which may be lacking from global model fields (here GFS). One potential solution to these issues involves a nesting approach, whereby the boundary condition methods of Torn et al. (2006) are applied on a coarse outer grid every $6 \mathrm{~h}$. These coarse grids then provide natural ensemble boundary conditions for use on the boundaries of finer inner grids.

Acknowledgments. This research was sponsored by National Science Foundation Grant ITR-0205648 and National Oceanic and Atmospheric Administration CSTAR Grant NA17RJ1232. The first author was also supported by a postdoctoral fellowship from the Swiss National Foundation for Sciences. We thank two anonymous reviewers for their constructive comments, which substantially improved the paper.

\section{REFERENCES}

Anderson, J. L., 2001: An ensemble adjustment filter for data assimilation. Mon. Wea. Rev., 129, 2884-2903.

Barker, D. M., W. Huang, Y.-R. Guo, and Q. N. Xiao, 2004: A three-dimensional (3DVAR) data assimilation system for use with MM5: Implementation and initial results. Mon. Wea. Rev., 132, 897-914.

Bishop, C. H., B. J. Etherton, and S. J. Majumdar, 2001: Adaptive sampling with the ensemble transform Kalman filter. Part I: Theoretical aspects. Mon. Wea. Rev., 129, 420-436.

Bormann, N., S. Saarinen, G. Kelly, and J.-N. Thépaut, 2003: The spatial structure of observation errors in atmospheric motion vectors from geostationary satellite data. Mon. Wea. Rev., 131, 706-718.

Derber, J., and F. Bouttier, 1999: A reformulation of the background error covariance in the ECMWF Global Data Assimilation System. Tellus, 51, 195-221. 
Dowell, D. C., F. Zhang, L. J. Wicker, C. Snyder, and N. A. Crook, 2004: Wind and temperature retrievals in the 17 May 1981 Arcadia, Oklahoma, supercell: Ensemble Kalman filter experiments. Mon. Wea. Rev., 132, 1982-2005.

Evensen, G., 1994: Sequential data assimilation with a nonlinear quasigeostrophic model using Monte Carlo methods to forecast error statistics. J. Geophys. Res., 99, 10 143-10 162.

Gaspari, G., and S. E. Cohn, 1999: Construction of correlation functions in two and three dimensions. Quart. J. Roy. Meteor. Soc., 125, 723-757.

Hamill, T. M., 2005: Ensemble-based atmospheric data assimilation: A tutorial. Predictability of Weather and Climate, T. Palmer, and R. Hagedorn, Eds., Cambridge University Press, 124-156.

— J. J. Whitaker, and C. Synder, 2001: Distance-dependent filtering of background error covariance estimates in an ensemble Kalman filter. Mon. Wea. Rev., 129, 2776-2790.

Houtekamer, P. L., and H. L. Mitchell, 1998: Data assimilation using an ensemble Kalman filter technique. Mon. Wea. Rev., 126, 796-811.

— atmospheric data assimilation. Mon. Wea. Rev., 129, 123-137.

,-- , G. Pellerin, M. Buehner, M. Charron, L. Spacek, and B. Hansen, 2005: Atmospheric data assimilation with the ensemble Kalman filter: Results with real observations. Mon. Wea. Rev., 133, 604-620.

Kalman, R. E., and R. S. Bucy, 1961: New results in linear filtering and prediction theory. J. Basic Eng., 83D, 35-45.

Keppenne, C. L., and M. M. Rienecker, 2002: Initial testing of a massively parallel ensemble Kalman filter with the Poseidon isopycnal ocean general circulation model. Mon. Wea. Rev., 130, 2951-2965.

Mitchell, H. L., P. L. Houtekamer, and G. Pellerin, 2002: En- semble size, balance, and model-error representation in an ensemble Kalman filter. Mon. Wea. Rev., 130, 2791-2808.

Murphy, J. M., 1988: The impact of ensemble forecasts on predictability. Quart. J. Roy. Meteor. Soc., 114, 89-125.

Nieman, S. J., W. P. Menzel, C. M. Hayden, D. Gray, S. T. Wanzong, C.S. Velden, and J. Daniels, 1997: Fully automated cloud-drift winds in NESDIS operations. Bull. Amer. Meteor. Soc., 78, 1121-1133.

Rabier, F., A. McNally, E. Andersson, P. Courtier, P. Unden, J. Eyre, A. Hollingsworth, and F. Bouttier, 1998: The ECMWF implementation of three-dimensional variational assimilation (3D-Var). II: Structure functions. Quart. J. Roy. Meteor. Soc., 124, 1809-1829.

Skamarock, W. C., J. B. Klemp, J. Dudhia, D. O. Gill, D. M. Barker, W. Wang, and J. G. Powers, 2005: A description of the Advanced Research WRF Version 2. NCAR Tech. Note 468+STR, National Center for Atmospheric Research, Boulder, CO, 88 pp.

Snyder, C., and F. Zhang, 2003: Assimilation of simulated Doppler radar observations with an ensemble Kalman filter. Mon. Wea. Rev., 131, 1663-1677.

Torn, R. D., G. J. Hakim, and C. Snyder, 2006: Boundary conditions for a limited-area ensemble Kalman filter. Mon. Wea. Rev., 134, 2490-2502.

Whitaker, J. S., and T. M. Hamill, 2002: Ensemble data assimilation without perturbed observations. Mon. Wea. Rev., 130, 1913-1924.

— G. P. Compo, X. Wei, and T. M. Hamill, 2004: Reanalysis without radiosondes using ensemble data assimilation. Mon. Wea. Rev., 132, 1190-1200.

Zhang, F., C. Snyder, and J. Sun, 2004: Impacts of initial estimate and observation availability on convective-scale data assimilation with an ensemble Kalman filter. Mon. Wea. Rev., 132, 1238-1253. 